NBER WORKING PAPER SERIES

\title{
WITH A LITTLE HELP FROM MY (RANDOM) FRIENDS: SUCCESS AND FAILURE IN POST-BUSINESS SCHOOL ENTREPRENEURSHIP
}

\author{
Josh Lerner \\ Ulrike Malmendier \\ Working Paper 16918 \\ http://www.nber.org/papers/w16918
NATIONAL BUREAU OF ECONOMIC RESEARCH
1050 Massachusetts Avenue
Cambridge, MA 02138
March 2011

We would like to thank a number of Harvard Business School officials and faculty who made this project possible, including Lynda Applegate, Angela Crispi, Lee Gross, Jim Heskett, Elizabeth Karpati, Jana Kierstaad, Joe Lassiter, Bill Sahlman, Coral Sullivan, and especially Mike Roberts, Toni Wegner, and Sarah Woolverton. Daniel Littlejohn-Carrillo, Lori Santikian, Rui Tang, Astha Tharpa, and especially Geraldine Kim and Rui Xu provided excellent research assistance. Helpful comments were provided by seminar participants at the American Finance Association meetings, Boston College, Harvard, MIT, the National Bureau of Economic Research, the University of Southern California, and Yale. Harvard Business School's Division of Research and the National Science Foundation provided financial support. All errors are our own. The views expressed herein are those of the authors and do not necessarily reflect the views of the National Bureau of Economic Research.

NBER working papers are circulated for discussion and comment purposes. They have not been peerreviewed or been subject to the review by the NBER Board of Directors that accompanies official NBER publications.

(C) 2011 by Josh Lerner and Ulrike Malmendier. All rights reserved. Short sections of text, not to exceed two paragraphs, may be quoted without explicit permission provided that full credit, including $\odot$ notice, is given to the source. 
With a Little Help from My (Random) Friends: Success and Failure in Post-Business School Entrepreneurship

Josh Lerner and Ulrike Malmendier

NBER Working Paper No. 16918

March 2011

JEL No. G24,I23,J24

\begin{abstract}
To what extent do peers affect our occupational choices? This question has been of particular interest in the context of entrepreneurship and policies to create a favorable environment for entry. Such influences, however, are hard to identify empirically. We exploit the assignment of students into business school sections that have varying numbers of classmates with prior entrepreneurial experience. We find that the presence of entrepreneurial peers strongly predicts subsequent entrepreneurship rates of students without an entrepreneurial background, but in a more complex way than the literature has previously suggested: A higher share of entrepreneurial peers leads to lower rather than higher subsequent rates of entrepreneurship. However, the decrease in entrepreneurship is entirely driven by a significant reduction in unsuccessful entrepreneurial ventures. The effect on the rate of successful post-MBA entrepreneurs, instead, is insignificantly positive. In addition, sections with few prior entrepreneurs have a considerably higher variance in their rates of unsuccessful entrepreneurs. The results are consistent with intra-section learning, where the close ties between section-mates lead to insights about the merits of business plans.
\end{abstract}

\author{
Josh Lerner \\ Harvard Business School \\ Rock Center 214 \\ Boston, MA 02163 \\ and NBER \\ jlerner@hbs.edu \\ Ulrike Malmendier \\ Department of Economics \\ 549 Evans Hall \# 3880 \\ University of California, Berkeley \\ Berkeley, CA 94720-3880 \\ and NBER \\ ulrike@econ.berkeley.edu
}




\section{Introduction}

The promotion of entrepreneurship has been a major focus of policymakers in recent years (see Kanniainen and Keuschnigg [2004]). Thousands of national and local initiatives have been launched in the belief that entrepreneurial activity is associated with the creation of wealth, technological innovation, and increased social welfare. Consistent with this assertion, cross-national studies (e.g., Djankov et al. [2002]) suggest that nations with greater barriers to entry of new firms also have poorer-functioning and more corrupt economies.

The concentration of entrepreneurs in regions such as Silicon Valley have led to speculation that interactions among high-skilled individuals with similar interests lead to large social multipliers in the "entrepreneurial production function," or, put another away, that there are powerful peer effects among entrepreneurs. Studies have shown that individuals who work at recently formed, venture-backed firms are particularly likely to become entrepreneurs (Gompers, Lerner and Scharfstein [2005]), as are those who work at companies where colleagues become entrepreneurs (Nanda and Sorensen [2010]) and in regions where many others opt for entrepreneurship (Giannetti and Simonov [2009]). All these studies suggest that peer effects are important determinants of entrepreneurial activity. However, their inability to fully control for unobserved heterogeneity or sorting of individuals into firms and locations means our interpretation of these results must be cautious.

A bigger, more conceptual issue is that the putative benefits to entrepreneurship are only likely to occur if ventures are successful. An emerging literature on "behavioral entrepreneurship" suggests that individuals may pursue new ventures even if the returns are predictably meager (Camerer and Lovallo [1990]; de Meza and Southey [1996]; Bernardo and Welch [2001]; Arabsheibani, et al. [2000]). Consistent with these claims, the high failure rates of entrepreneurial ventures are well-documented (see, for instance, Davis, Haltiwanger, and Schuh [1998]). ${ }^{1}$ The returns to society of attracting substantial

\footnotetext{
${ }^{1}$ Landier and Thesmar [2009] find that firms run by optimists - a characteristic that has been shown by Evans and Leighton [1989] to be associated with the decision to become entrepreneurs - grow less, die sooner, and are less profitable, despite the fact that these owners tend to put in more effort.
} 
numbers of talented people into unsuccessful ventures are unlikely to be high. ${ }^{2}$ Much of the previous research, including the work on peer effects in entrepreneurship, has focused on what induces entrepreneurship, without distinction between successful and unsuccessful ventures.

In this paper, we distinguish between successful and unsuccessful entrepreneurship and make methodological progress in identifying peer effects in entrepreneurship. We exploit the exogenous assignment of entrepreneurial peers among Masters of Business Administration (MBA) students at Harvard Business School (HBS). At HBS, school administrators exogenously assign students into sections that spend the entirety of their first year in the program studying and working together. These sections form extremely close ties, and are a setting where peer effects - if they are empirically observable at all —would be likely to be seen. We exploit the fact that the representation of students with entrepreneurial backgrounds varies considerably across sections to evaluate the impact of peers on the decision to become an entrepreneur. Moreover, we collect detailed data about the students' entrepreneurial ventures, which allow us to differentiate between successful and unsuccessful start-ups and to relate peer effects to entrepreneurial success.

In addition to the appeal of the exogenous assignment and the availability of success measures, this setting is attractive since it overcomes limitations of the primary data sources used in previous entrepreneurship research, such as Census data, Internal Revenue Service data, and the Panel Study of Entrepreneurial Dynamics. Those data allow only a specific type of entrepreneurial activity to be observed. As highlighted by Parker [2004], most empirical studies have focused on the self-reported decision to become self-employed (e.g., as a groundskeeper or consultant) rather than the founding of an entrepreneurial firm. In fact, in many databases, founders of entrepreneurial companies cannot be distinguished from employees of established firms. In our setting, we can carefully trace the entrepreneurial histories of the students.

A second challenge facing much of the earlier empirical work is that the

\footnotetext{
${ }^{2}$ An even deeper issue is that some entrepreneurial ventures may be privately lucrative but add little to the welfare of society as a whole. Baumol [1990] and Murphy, Shleifer, and Vishny [1991], for example, highlight the distinction between productive and unproductive entrepreneurship and argue that the social consequences are dramatically different.
} 
importance of entrepreneurial entities varies tremendously. While the bulk of entrepreneurial ventures simply replicate other entities and have limited growth potential (Bhide [2000]), a small number of ventures create enormous wealth and have a profound economic impact. Our data include a significant number of high-potential start-ups. Historically, Harvard Business School students have been instrumental in founding leading firms in a variety of industries (e.g., the Blackstone Group, Bloomberg, LLP, and the modern Xerox Corporation; for many more examples, see Cruikshank [2005]). Even within our relatively recent sample, we encounter early-career HBS entrepreneurs founding highly successful firms, such as athenahealth (publicly traded, with a market capitalization of $\$ 1.5$ billion in March 2011) and SupplierMarket (acquired by Ariba for \$581 million).

We analyze the effect of students with prior entrepreneurial experience on the post-MBA entrepreneurship among their section-mates (without prior experience). Using data from class cards of 5,897 students of the classes 1997 to 2004, section-level postMBA placement data, and hand-collected data on the success of entrepreneurial ventures, we create a novel data set to test for entrepreneurial peer effects.

We find a striking pattern: exposure to a higher share of peers with a pre-MBA entrepreneurial background leads to lower rates of entrepreneurship post-MBA. A one standard deviation increase in the share of peers with a pre-MBA entrepreneurial background in a section (evaluated at the mean of all independent variables) reduces the predicted share of the other students going into an entrepreneurial role after graduation by about one percentage point, a reduction of more than twenty-five percent. This finding is seemingly at odds with the prior literature evaluating peer effects, though our setting (peer effects among business school students) precludes a direct comparison.

When we differentiate between successful and unsuccessful ventures, however, we find that the negative peer effect is exclusively driven by a decrease in unsuccessful entrepreneurship. The share of students who start ventures that do not achieve critical scale or other measures of success is significantly and negatively related to the representation of pre-MBA entrepreneurs. Meanwhile, the share of successful post-MBA entrepreneurs is positively related, though the effect is typically not significant. The differences between the impact of prior entrepreneurs on the successful and unsuccessful 
post-MBA entrepreneurship rates are statistically significant.

These results are consistent with the presence of intra-section learning. An extensive literature, beginning with Jovanovic [1982], has highlighted the fact that entrepreneurs learn about their abilities through running their businesses. The close ties between students in the same section may accelerate the learning process about prospective business ideas.

There are several possible channels for such intra-section learning, which we explore in further empirical tests. First, students seeking to start new ventures could be benefitting from the direct counsel of their peers. Students with entrepreneurial backgrounds may help in identifying which business ideas are problematic and which ones are worth pursuing. Second, the mere presence of entrepreneurial peers and their reports about their experiences may help other students to realize the challenges involved in starting a company. That is, even without individual advice, pre-MBA entrepreneurs may inject realism into other students and discourage all but the best potential entrepreneurs from pursuing their ventures. Third, the presence of entrepreneurial peers may not affect individual decisions directly, but encourage students to take more elective entrepreneurship classes, which in turn leads to better decisions.

We address the third mechanism by examining the enrollment in second-year entrepreneurship classes. We find that, in sections with more entrepreneurial peers, students without a prior entrepreneurial background are neither less nor more likely to enroll in elective entrepreneurship classes, ruling out the third explanation. This finding also casts doubt on the second explanation, since the stimulus of the "mere presence effect" would suggest less enrollment. In addition, we also test whether prior entrepreneurs' own (prior) success or failure is related to the sign or strength of the peer effect, as one would have expected if the mere exposure to the reports of prior entrepreneurs explains our findings. We do not find any such correlation. Hence, while the lack of micro-data on individual student-level interactions limits our ability to test the causal role of direct student interaction, the empirical patterns seem most consistent with this interpretation. This explanation is also consistent with our last finding: the variance of post-MBA entrepreneurship rates is significantly lower when relatively many entrepreneurs are present in the section. One interpretation of the reduction in variance is 
that, with a large enough number of entrepreneurial peers, at least one of them will have the expertise to detect the flaw in a given business idea.

In addition to helping understand peer effects in entrepreneurship, our analysis is relevant to policy-makers, business school faculty, and administrators. ${ }^{3}$ Business schools are putting significant energy and resources into the promotion of these activities, often with public subsidies. For instance, during the 1990s and early 2000s, U.S. business schools created over 300 endowed chairs in entrepreneurship, typically paying salaries that were significantly higher than those in other business disciplines (Katz [2004]). Several hundred business plan contests for business school students were also launched during these years. The results of this paper suggest a slight redirection in educational and policy initiatives. Much of the benefit from exposure to entrepreneurship appears not to come from encouragement of more entrepreneurship but from help in weeding out ventures that are likely to fail. Rather than focusing on the attraction of more people into entrepreneurship, schools and policy-makers may want to provide support to would-be entrepreneurs in critically evaluating and identifying their most promising ideas.

The plan of this paper is as follows. Section II describes identification issues. We describe the construction of the sample in Section III. Section IV presents the analysis. The final section concludes the paper.

\section{Identification}

Our identification strategy exploits three unique features of the data we collected. The first is the exogenous assignment of students to sections (and the strong role of sections at Harvard Business School). Second is the distinction between students with and without prior entrepreneurial experience, i.e., the ability to distinguish between students who will possibly exert an entrepreneurial influence and those who are less likely to do so. Finally, while much of the literature on entrepreneurship has been hampered by including a broad range of self-employment as entrepreneurship, we obtain information about the scale and success of the entrepreneurial ventures. Hence, our paper provides not only a clean (and different) answer to the question whether exposure to

\footnotetext{
${ }^{3}$ To our knowledge, the only papers examining entrepreneurial choices among MBAs are Lazear [2005] and Eesley, Hsu and Roberts [2007]. Both have quite different focuses.
} 
entrepreneurial peers increases entrepreneurship, but also whether entrepreneurial peers help in making the "right" decision.

\section{II.A. Challenges in Identifying Peer Effects}

The appropriate identification of peer effects is a major challenge in economics. Earlier papers measured peer effects by using observational data and regressing entrepreneurship outcomes on entrepreneurship among peers. There are several challenges in interpreting coefficients estimated with this approach (Manski [1993], Sacerdote [2001]). The most important issue is self-selection. If individuals choose the firm or other location of interaction with their peers, it is difficult to separate out the selection effects from actual peer effects. In fact, several studies in the economics of education show that peer effects found in settings with endogenous sorting tend to disappear once the analysis is redone exploiting exogenous assignment, regardless of how extensively observables are controlled for in the settings with endogenous sorting. Kremer and Levy [2008], for example, study the peer effects of college students who frequently consumed alcohol prior to college on the GPA of their roommates and find systematic differences in the sample of randomly assigned and the sample of self-selected roommates. Another example is the decision to invest in a retirement. Duflo and Saez [2002] analyzed the influence of co-workers in a setting with endogenous sorting. When they re-analyzed the effect in the context of a randomized experiment (Duflo and Saez [2003]), they found significantly smaller (if any) peer effects. In this paper, we are able to move beyond these limitations by exploiting exogenous variation in the exposure to entrepreneurial peers. Our identification strategy is discussed in more detail in the next subsection.

Another confounding issue in the prior literature on peer effects is the distinction between the effect of one peer on others, on the one hand, and common shocks affecting the entire peer group, on the other hand. In the context of school outcomes, for example, Sacerdote [2001] finds a significant correlation in the GPAs of randomly assigned college roommates but little evidence that students are affected by their roommate's pre-college academic background (SAT scores and high-school performance). Hence, as discussed in Kremer and Levy [2008], common shocks due to dorm room characteristics, infections, or joint class choices might be influencing both roommates and explain part of the 
results. Focusing on pre-determined characteristics, such as entrepreneurial activities prior to graduate school, avoids this problem.

\section{II.B. Sections at Harvard Business School}

Harvard Business School has long used a section system, which allows us to address the above-mentioned identification challenges. Students spend their first year of the MBA program in groups of 80 to 95 students in a single classroom, taking a fixed slate of classes (e.g., accounting, finance, and marketing) with a set group of peers. There is no provision for switching between sections. While administrators ensure that each section is taught by a mixture of junior and senior faculty, no effort is made to match faculty and section characteristics. While in their second year of the program, students take elective courses with the entire student body. The social ties established in the first year appear to remain extremely strong, even after graduation. For instance, at $25^{\text {th }}$ reunions of HBS alumni, fundraising and many activities are arranged on a section-bysection basis.

The power of the social experience engendered by HBS sections has been observed upon in both journalistic accounts and academic studies. For instance, in his account of Harvard Business School life, Ewing [1990] observes:

If the Harvard Business School has a secret power, it is the section system. A first-year section has a life of its own, bigger than any student, more powerful than any instructor... All first-year instructors I know agree about the awesome power of the section. They may not like the way it works in all cases - who does-yet it drives B-school students to learn, influencing them in countless ways.

Similarly, in a field-based analysis of the first-year HBS experience, Orth [1963] highlights the extent to which students in sections, "in order to insure feelings of safety and, if possible competence in a situation that is initially perceived to them to be threatening," adopt "norms" that affect study patterns, social interactions, and even choices regarding employers with which to interview. He notes that "some norms appeared to be common to all first-year sections and others appeared to develop as a result of a particular section's pattern of adaptation to the conflicts and pressures of the first year."

Given the persuasive influence of the section experience, it is not surprising that it 
affects the decision to become an entrepreneur. Cruickshank [2005] offers a number of illustrations where section-mates began businesses or refined business ideas together. Another place to see the impact of the section relationships on entrepreneurial choices is the HBS business plan contest. This competition, begun in 1997, was open in its initial years only to second-year students. Many of the entries in the business plan contest were the foundation for post-MBA ventures. Despite their freedom to choose partners across their entire class, the students disproportionately chose partners who had been in their first-year sections. In the business plan contests between 1998 and 2004, there were 277 student teams consisting of 566 pairs of second-year students. ${ }^{4}$ Of the pairs of the secondyear HBS students who entered the contest together, 185 pairs, or $33 \%$, consisted of section-mates. Were the selection of fellow students random across sections, the expected share of section-mates would have been 9\% for the classes of 1998 through 2003 and $10 \%$ for 2004 .

A second reason why the assignment to varying section environments is a promising path to explore entrepreneurial peer effects is the professional experience of the students prior to entering business school. Unlike many other professional schools, HBS students have considerable work experience prior to matriculation. In the classes under study, the typical student had between three and five years of post-college work experience. ${ }^{5}$ Moreover, there is a considerable degree of diversity in terms of the backgrounds of the students across sections, which allows us to exploit the differences across sections empirically.

\section{II.C. Assignment to Sections}

Students are assigned into sections by a computer program developed by HBS administrators whose assignment procedure is a mixture of randomization and stratification. The information used in the sectioning process is derived largely from forms that students fill out, which also serve as the basis of the class cards that we analyze. The program to assign students to sections has undergone slight modifications

\footnotetext{
${ }^{4}$ Students were allowed in these years to involve students from other schools but not first-year students. In our calculations, we consider all pairwise combinations, ignoring non-HBS students. For example, a team consisting of three students, hailing from sections A, B, and B, was regarded as involving three pairs, one of which consisted of students in the same section and two of which did not.

${ }^{5}$ http://www.hbs.edu/about/mba.html (accessed November 17, 2007) and unpublished tabulations.
} 
over the years, but worked as follows during the period under study: First, approximately 200 students are randomly chosen out of all entering students and randomly assigned to sections. Then, the program considers additional students one at a time in random order, and assigns them to a section based on a stratification score. This score is a weighted average of the Herfindahl index of each measure used to assign students. The program computes which assignment would make the weighted average Herfindahl index lowest, and assigns the student to that section. The primary considerations behind the stratification of students into sections are, in order of priority (and hence weight):

a. Gender.

b. Ethnicity.

c. Whether the student went to the remedial analytics course in August prior to matriculation, and if so, what (remedial) section the student was assigned to.

d. Quantitative and verbal skills, in particular, whether the student's admission was conditional on a remedial analytics course, supplemental work on quantitative skills, or work on verbal skills, and whether the student's quantitative or verbal GMAT score was high, medium, or low.

e. Home region. (The system distinguishes ten US regions, most major European countries, Japan, China, India, and elsewhere.)

f. Industry in which the student worked in his/her most recent job (e.g., consulting, finance, telecommunications, etc.).

g. Age.

h. Whether the student attended one of the major "feeder" colleges (Harvard, Yale, West Point, etc.).

i. Function in the student's last job (sales, finance, etc.). Students who had been entrepreneurs prior to business school are classified as general management, but so are many others, such as those working in leadership positions at non-profits and as junior officers in the military. ${ }^{6}$

j. Marital status.

k. College major.

\footnotetext{
${ }^{6}$ Other examples include the program director at a sports training academy, an associate at a foundation, general managers of restaurants, and the senior manager of new business development at a heath-care firm.
} 
1. Whether the student worked for one of 49 major companies in their last job. Due to software limitations the program requires an exact match, which works very poorly. For instance, it recognizes "McKinsey \& Co." or "McKinsey \& Company," but not "McKinsey" or "McKinsey Chicago." For example, out of approximately 450 admits in the class of 2010 that we examined, the program only recognized the firms for about $10 \%$. All others were bunched together in "other," along with former entrepreneurs and students who worked for smaller firms.

Once a section fills up (reaches capacity), the assignments are only made to the remaining sections. Finally, the registrar staff "hand-adjust" these assignments to correct for two crucial considerations the program misses:

- Identifying students who are born to expatriate parents. For example, a student born in the U.S. with French citizenship (which suggests French parents) may be switched to a section with fewer French people.

- Identifying students with a military background whom the program missed because of a brief stint on Wall Street or consulting before going to business school. Students will be swapped to ensure the military component in each section is about even.

Hence, the primary dimensions along which students are sorted are essentially orthogonal to the ones of interest of our study. Secondary considerations in assigning students to sections, such as undergraduate institutions-e.g., Ivy League vs. state university graduates - are not completely orthogonal to the variable of interest. However, stratification along these dimensions does not bias our identification. It only may lower the power of our analysis. We had access to all information used about the students in the sectioning process (or approximations of that information) with the exception of that on test scores and conditional admissions (items $\mathrm{c}$ and d). Most importantly, because the administrators do not undertake the detailed textual analysis we do (see below), the section assignment software uses only the subset of the class card information that can be readily sorted by the computer. In particular, they do not identify and balance out those students who were entrepreneurs prior to HBS.

\section{II.D. Identifying Peer Effects}

One difficulty in estimating peer effects is the distinction between the influence 
entrepreneurial classmates exert on others as opposed to themselves, i.e., their own greater propensity to return to entrepreneurship. Suppose we would like to identify, for each student, the entrepreneurial peer effect of all other students as well as the role of the student's own prior experience. A simple individual-level regression model can be written as follows:

$$
Y_{i, j}=\alpha+\beta \bar{X}_{-i, j}+\gamma X_{i, j}+\delta X_{i, j} \times \bar{X}_{-i, j}+\text { other effects }
$$

where $i$ indicates the individual student, $j$ the section, and $Y_{i j}$ is an indicator equal to 1 if student $i$ became an entrepreneur post-MBA; $\bar{X}_{-i, j}$ is the peer effect (share of pre-MBA entrepreneurs in section $j$ excluding student $i$ ); and $X_{i, j}$ is an indicator equal to 1 if student $i$ was a pre-MBA entrepreneur.

Summing up the individual-level data by section and dividing by the total number of students in a section, we obtain the section-level regression model:

$$
\begin{aligned}
& \bar{Y}_{j}=\alpha+\beta \bar{X}_{j}+\gamma \bar{X}_{j}+\delta \frac{N_{j}}{N_{j}+M_{j}} \frac{N_{j}-1}{N_{j}+M_{j}-1}+\text { other effects } \\
& \Leftrightarrow \bar{Y}_{j}=\alpha+(\beta+\gamma) \bar{X}_{j}+\delta \bar{X}_{j} \bar{X}_{j}{ }^{\prime}+\text { other effects }
\end{aligned}
$$

where $\bar{Y}_{j}$ is the share of post-MBA entrepreneurs in section $j ; \bar{X}_{j}$ is the share of preMBA entrepreneurs in section $j ; \bar{X}_{j}^{\prime}$ is the share of all but one pre-MBA entrepreneur relative to section size minus 1 (and is 0 if there is no or only one pre-MBA entrepreneur); $N_{j}$ is the number of pre-MBA entrepreneurs in section $j$; and $M_{j}$ is the number of non-pre-MBA entrepreneurs in section $j$. Equation (3) illustrates that we cannot separately estimate the peer effect of others' entrepreneurial experience $(\beta)$ and of students' own entrepreneurial experience $(\gamma)$. Instead, we are measuring the combined effect $(\beta+\gamma)$. In addition, the interactive effect $\bar{X}_{j} \bar{X}_{j}^{\prime}$ complicates the estimation.

However, differently from the typical setting in the entrepreneurial peer effects literature, our empirical approach allows us to distinguish between individuals who exert entrepreneurial peer influence and those who do not, namely, students with and without prior entrepreneurial experience. By excluding pre-MBA entrepreneurs from the sample, we can estimate peer effects independently of the effects of pre-MBA entrepreneurs on themselves. In such a reduced sample, the above individual-level regression becomes: 


$$
Y_{i, j}=\alpha+\beta \bar{X}_{-i, j}+\text { share of other effects }
$$

where $i$ now indicates an individual student without prior entrepreneurial experience, $i \in\left\{i \mid X_{i, j}=0\right\}$. As before, $Y_{i, j}$ is an indicator equal to 1 if student $i$ became an entrepreneur post-MBA, and the peer effect $\bar{X}_{-i, j}$ the share of pre-MBA entrepreneurs in section $j$ excluding student $i$. Since all students in the reduced sample have no prior entrepreneurial experience, $\bar{X}_{-i, j}$, is identical for all $i$ and amounts to the fraction of preMBA entrepreneurs relative to the size of section $j$ minus 1: $\bar{X}_{-i, j}=$ $\sum_{\hat{i} \neq i} X_{\hat{i}, j} /\left(N_{j}+M_{j}-1\right)=N_{j} /\left(N_{j}+M_{j}-1\right)$. Finally, the third term and the fourth (interaction) term form equation (1) disappear since $X_{i j}=0$ for all $i$ in the new sample.

Summing up over all non-prior entrepreneurs $i \in\left\{i \mid X_{i, j}=0\right\}$ by section $j$ and dividing by their total number $M_{j}$, we obtain the new section-level model:

$$
\bar{Y}_{M_{j}}=\alpha+\beta \bar{X}_{-1, j}+\text { share of other controls }
$$

where $\bar{Y}_{M_{j}}$ indicates the fraction of students becoming entrepreneurs among all students without prior entrepreneurial experience, $\bar{Y}_{M_{j}}=\sum_{i \in\left\{i \mid X_{i, j}=0\right\}} Y_{i, j} / M_{j}$. We use model (5) for our regression analysis.

\section{The Data}

Our analysis draws on four primary sets of data. These data sources characterize the incoming student body and their first-year sections, elective course choices in the second year, career choices upon graduation, and the ultimate outcomes of entrepreneurial ventures, respectively.

First, we collect data on the characteristics of students in the classes graduating between 1997 and 2004 from their class cards. The starting date was dictated by data availability; the end date by the need to have several years after graduation in order to identify which entrepreneurs were successful. The class cards are initially filled in by school administrators based on students' applications. ${ }^{7}$ Students can update their class

\footnotetext{
${ }^{7}$ The fact that the information in the class cards is drawn from applications helps address concerns that students exaggerate their accomplishments on the cards to impress peers. Lying on one's application is a
} 
cards while enrolled at HBS.

We obtain the class cards for 6,129 students and extract information on gender, nationality (in particular, sole or joint U.S. citizenship), age, family status, educational background, and work experience. Due to inappropriately classified students (e.g., cross registrants) and missing data, the usable data set amounts to 5,897 students. For age, we use 21.5 years plus the time elapsed since college graduation as the age at matriculation at $\mathrm{HBS}^{8}{ }^{\circ}$ For family status, we use their response to a query as to whether they had a partner, as well as whether they indicated children among their interests or other descriptive material. In terms of work experience, we identify the industry where each student had worked after graduation from college. Students who worked in multiple industries (e.g., investment banking and private equity) are coded as having participated in both. ${ }^{9}$

We characterize the educational background of the students in two ways. As one approach, we identify primary degrees from Ivy League schools. As an alternative approach, we use "Ivy Plus" schools (an association of administrators of leading schools), which includes the Ivy League schools as well as the California Institute of Technology, the University of Chicago, Duke University, the Massachusetts Institute of Technology, Stanford University, and the Universities of Cambridge and Oxford. In unreported analyses, we also add the top non-U.S. schools (as defined by the Times Higher Education Supplement) in addition to Cambridge and Oxford: the Ecole Polytechnique and the London School of Economics. These changes make little difference to the results.

Going beyond the baseline characteristics used by HBS for stratification, we also attempt to characterize students' risk attitudes, given suggestive evidence in the literature

very high-risk strategy, as it can lead to expulsion from the school or even the voiding of a degree. HBS takes ethics during the application process very seriously: for instance, several years ago, some accepted students who had checked the status of their application on a web site earlier than allowed had their offers rescinded (Broughton [2008]).

${ }^{8}$ This calculation is based on estimates by school administrators. While U.S. Census data suggests that the average graduate of an undergraduate program is considerably older, the majority of the school's enrollees complete their programs faster. (The primary exceptions are Mormon students, who frequently take two years off from college to serve as missionaries).

9 We use a sixty-industry scheme employed in the hiring and compensation database of HBS Career Services. In an unreported analysis, we explore the robustness of the results to assigning each student to a single field - the one in which he or she spent the most time. (If a student worked an equal amount of time in two fields, we choose the area in which he or she worked most recently before beginning business school, as they are likely to have had more responsibility there.) The results are little changed. 
on the lower risk-aversion of entrepreneurs (Parker [2004]). As an imperfect proxy, we exploit the riskiness of the activities listed by the students based on the injury data from American Sports Data [2005]. ${ }^{10}$ We employ their compilation of "Total Injuries Ranked by Exposure Incidence," which gives the number of injuries per 1000 exposures for each sport. The most risky activity (boxing) causes 5.2 injuries per 1000 exposures and gets a risk score of 1 . Other activities are scaled accordingly. Lacrosse, for example, causes 2.9 injuries per 1,000 exposures and gets a risk score of 2.9/5.2 $=0.558$. We average the top risk score for each student in the section. In unreported robustness checks, we employ the average across all activities listed by each student. We also calculate the share of students in each section whose top risk scores are higher than certain thresholds - mean $(0.38)$, mean plus one standard deviation (0.48), and mean plus two standard deviations (0.58) as the risk-seeking students are the ones who might be more likely to become entrepreneurs. Again, the results are little different.

Finally, we use the class cards to identify the key variable for our analysis of entrepreneurial peer effects: prior (pre-MBA) entrepreneurial experience. We identify students who founded or co-founded an entrepreneurial venture prior to entering business school. We do this by searching for terms such as "co-founded," "started," or "launched." We include ventures which are spun-off from another firm, but eliminate corporate ventures, e.g., starting up and heading a division within a company. ${ }^{11}$ Unlike the calculation of industry experience (which focused on post-college employment), we include businesses begun before graduating from college, on the grounds that these experiences also provide insights into the planning and implementation of entrepreneurial ventures.

Overall, the prior entrepreneurial endeavors were quite diverse, but most fell into

\footnotetext{
${ }^{10}$ The data is based on a survey of 25,000 households in 2003 (62\% response rate). Several injury measures are provided, e.g., total injuries, injuries resulting in an emergency room visit, etc., which tend to be quite correlated. For sports not included in the American Sports Data, we substitute the closest sport (e.g., baseball for cricket, day hiking for orienteering). If there is no comparable listing, we assign the top ranking if they appear to be very high risk (e.g., motorcycle racing) and the median ranking if they are more moderate (for instance, fencing). We exclude activities that do not involve physical exertion (e.g., fantasy football and pigeon racing) or that were too vague to be classified (for instance, "athletics" or "all sports").

${ }^{11}$ Freelance consulting is not counted as starting a business unless there are other consultants working for that person. We also do not include a small number of cases where students operated franchises as entrepreneurs since operating a franchise is more similar to running a corporate unit.
} 
three broad categories:

○ Businesses geared toward a limited market. Frequent examples included campusoriented services (e.g., a bottled water delivery service to dorm rooms at local college campuses) and food service facilities (e.g., a 14-unit retail bagel chain in Hungary).

- Businesses that were acquired due to economies of scale or scope, such as a chain of eight bike shops sold to a larger competitor, or an Internet consulting firm that was sold to a more generally focused consulting firm after a failed IPO.

○ Ventures where the entrepreneurial founder was eventually shunted into a narrower functional role (e.g., chief technology officer) as the firm grew and professional management was recruited, such as security software firm.

We also assess the success of those prior entrepreneurial ventures. If there are entrepreneurial peer effects, the influence of successful entrepreneurs may be more encouraging than that of unsuccessful entrepreneurs. Our primary cut-off point for success is whether the business achieved a million dollars in annual revenues. ${ }^{12} \mathrm{We}$ determine this information through descriptions in the class cards, social networking sites such as Facebook and LinkedIn, and direct contacts with the students. In total, $42 \%$ of the businesses were classified as successful, 19\% as unsuccessful, and the remainder as unknown. The success rate is unusually high compared to broader samples of entrepreneurs. Apparently, pre-HBS entrepreneurs often sold their businesses at a profit, and chose to enter an MBA program with the intention to go for new and larger ventures. We encountered descriptions such as "grew business from start-up to $\$ 6$ million per year in revenues - my brother is managing now," or "took \$2 million in profits out of business in three years before wrapping it up."

To better understand the selection of entrepreneurs entering the MBA program, we conducted a number of interviews with MBAs who had been entrepreneurs prior to business school. They all emphasized their need for skill development. Many had been technically trained prior to business school and had little by way of business training or insights into marketing, finance, etc. That deficiency, they highlighted, had become increasingly important as their businesses grew and they interacted with individual angel

12 Note that the cut-off is lower than in the definition of the success for post-business school entrepreneurship. The lower hurdle reflects that students engaging in pre-business school entrepreneurship had a lower opportunity cost. 
investors and venture capitalists. The other main motivation they mentioned was the desire for more contacts. Several respondents expected ties with venture investors, corporate development specialists, and wealthy people in general to result from enrollment at HBS, which would increase the probability of success of future ventures.

A major difficulty in the data collection process was posed by the failure of HBS to archive class cards prior to 2000. For the period between 1997 and 1999, we obtained the cards from HBS professors who had saved the class cards of their former students. Some of these instructors had taught first-year classes, in which case they had information on all the students in a given section. Others had taught second-year classes, in which they had cards on an assortment of students across various sections. As a result, the completeness of our information about sections in the early years varies.

Missing class cards reduce the precision with which we can characterize the features of sections and raise concerns about response bias. In high-count sections, for which we have all or almost all class cards, the cards are either provided by HBS or by first-year instructors, who are assigned randomly to sections. Thus, there is little potential for bias. In low-count sections, instead, the cards come from second-year instructors. Only a minority of instructors saves the cards of former students, and these are typically professors of management practice (successful practitioners who become instructors after their business careers) and professors in more practically minded fields such as entrepreneurship. Hence, the class cards available in low-count sections characterize the selected set of students who, in their second year, choose to register in classes with these professors. In order to address concerns of such selection biasing our result, the main analyses reported in the paper only employ sections where we have been able to gather at least seventy class cards. In addition, we undertake supplemental analyses with all sections and with a less restrictive sub-sample (sections with at least 40 class cards). ${ }^{13}$

Tables I and II show the summary statistics. Unlike in the rest of the paper, Table I displays aggregate data on the entire student body, including students for whom we are missing class cards. The year-by-year statistics reveal that, while class size remained

\footnotetext{
${ }^{13}$ In the more expansive samples (all sections or all sections with $40+$ class cards), we also replicated our analyses weighting the observations by the number of class cards. The main results are robust to all of these alternative approaches, though in some cases the levels of statistical significance are lower - as predicted by the underlying selection. All replication tables are available from the authors.
} 
approximately constant, around 900 across all sections, the composition changed: female, minority, and non-U.S. students were increasingly represented. In addition, the share of students with technical training increased markedly. The average section size remained stable, around 80 students, from the class of 1998, when an additional section was added and the average section size shrank in conjunction with an experimental accelerated MBA program, until the class of 2004, when the number of sections was reduced from 11 to 10 shortly after the elimination of the program (resulting in an increase in section size). The lower half of Table I shows measures of macro-economic financing conditions, which we use to control for the U.S. economic environment for entrepreneurship. One measure is the amount of U.S. venture capital financing. Venture capital is an important mechanism for funding new growth firms, including many of the ventures begun by Harvard MBAs. We compile the amounts provided annually in the initial and in all financing rounds. The information is taken from National Venture Capital Association [2005], based on the records of Venture Economics. Another measure, compiled from Securities Data Company and the website of Jay Ritter, is the number and dollar volume of initial public offerings in United States, as well as the amount "left on the table" in these offerings (the difference between the closing price on the first day and the offer price, multiplied by the number of shares sold). Even though IPOs are typically confined to firms that have several years of operations, they provide a useful proxy of VC financing available to new ventures in the same industry, possibly reflecting investment opportunities in this industry (Gompers, Kovner, Lerner, and Scharfstein [2008]). The year-by-year tabulation in the lower half of Table I highlights the acceleration of activity during the "bubble years" of the late 1990s. This pattern is also illustrated in Figure 1. In our regression analysis, we employ both a $\mathrm{VC}$ and an IPO measure of financing conditions. (The results are robust to the choice of measures.) Alternatively, we include year dummies.

Table II shows more detailed characteristics for those students for whom we have class card information. We aggregate by section to make the data compatible with the outcome data, post-MBA entrepreneurship, which is available only by section (as described below). Panel A shows the summary statistics for all 86 sections, and Panel B for the 60 sections where we were able to gather at least seventy class cards. In terms of 
control variables, the data reveals the heavy representation of students in investment banking and consulting. ${ }^{14} \mathrm{We}$ also single out the share of students working in private equity (which we define here to include both venture capital and buyout funds), since these students may be particularly well prepared to provide counsel to would-be entrepreneurs. Sections differ on a variety of personal characteristics, including the presence of students with children and graduates of elite schools. The differences between the $10^{\text {th }}$ and $90^{\text {th }}$ percentiles narrow somewhat when we require data on at least 70 students (Panel B), which reflects the fact that the distribution becomes less noisy.

The key variable of interest is the share of students who previously worked as entrepreneurs. In both panels, the average is around 5\%, though the range is quite large, between one and ten percent. The scatter plot in Appendix Figure 1 shows the full range of variation (for our main sample of sections with 70 or more class cards) by plotting the year-section data points, ordered by section.

To distinguish time-series from cross-sectional variation, we graph the full distribution of the number of entrepreneurs per section on a (raw) count basis (the left graph in Figure 2A) next to the distribution adjusted for year effects, namely, the share of pre-MBA entrepreneurs in a section divided by the average share in that year (the right graph in Figure 2A). The two graphs show that, while some sections have no members with previous entrepreneurial ventures, others have up to 13\% (12 pre-MBA entrepreneurs) and, year-adjusted, a rate nearly three times the rate of the other sections in that year. The year-by-year variation, instead, is somewhat smaller. As shown in Figure $2 \mathrm{~B}$, the share of students that have had entrepreneurial experience varies between $3.7 \%$ in 1998 and $6.3 \%$ in 1997.

Our second data set contains the students' elective class choices in their second year. As noted above, the different possible explanations for the patterns of peer effects have differing implications for enrollment in the elective entrepreneurship classes in the second year. We determine all elective classes students enrolled in, as well as the fraction of such classes listed as (co-)sponsored by the Entrepreneurial Management unit in the course prospectus. For all the students without prior entrepreneurial experience in a given

\footnotetext{
${ }^{14}$ The variation in the share of investment bankers $\left(10^{\text {th }}\right.$ versus $90^{\text {th }}$ percentile $)$ reflects in large part timeseries variation, i.e., the ebb-and flow of these admits across classes, rather than inter-section differences.
} 
section, we compute the share of entrepreneurship classes. On average, non-entrepreneurs in a given section devote $19 \%$ of their elective classes to entrepreneurship. The ratio varies from as low as $9 \%$ to as high as $27 \%$.

Our third data set provides information related to the choice of careers post-graduation and hence the key outcome variable, post-MBA entrepreneurship. We use the annual HBS "exit survey." Since HBS makes the picking of a cap and gown for graduation conditional on survey completion, participation is very high. The survey offers multiple choice categories to characterize the post-graduation employment (i.e., for industry of employment), as well as for cases where the student is still looking for employment and where the student has founded or is planning to imminently found a new venture. The survey responses are anonymous, in order to ensure candid responses. We identify all cases where students had or were beginning an entrepreneurial venture. We obtained access to this data aggregated on the section level.

It should be noted that the survey only reflects students' intentions at the time of graduation. It is possible that some would-be entrepreneurs abandon their quests later, maybe due to receiving an attractive job offer. And, vice versa, graduates may decide to start a company later. Thus, the data do not capture any long-term impact entrepreneurial peers have on their section-mates' decisions to start a company. The survey also does not characterize the career choices of students who drop out without completing a degree. This (very small) fraction, typically considerably under $1 \%$, overwhelmingly represent students who leave the program involuntarily due to poor academic performance. Even at the peak of the Internet boom, only a handful of students permanently left school before graduation to pursue an entrepreneurial opportunity.

The final element of the data preparation had to do with separating out, among those who became entrepreneurs after finishing the MBA program, the shares of students who also had prior entrepreneurial experience. As discussed in the previous section, we would like to exclude "pre-and-post-MBA" entrepreneurs from the estimation of peer effects to obtain identification and to distinguish the estimated peer effect from the effect of own prior experience. Hence, our desired outcome variable $\bar{Y}_{M_{j}}$ is the fraction of students in section $j$ who become entrepreneurs post-MBA among all students in that 
section who had no prior entrepreneurial experience: $\bar{Y}_{M_{j}}=\sum_{i \in\left\{i \mid X_{i, j}=0\right\}} Y_{i, j} / M_{j}$. The empirical difficulty in estimating the peer effects exclusively on students who were not entrepreneur before lies in the anonymity of the placement data. As noted above, we obtain those data compiled by section. To create the desired ratio, we needed to identify, for all sections $j$, the number of students with prior entrepreneurial experience who also started a (new) company post-MBA.

We use our individual-level class card data to extract information on each of the students with prior entrepreneurial experience and research if they took an entrepreneurial position after HBS. The main sources of additional information were social networking sites, Google, and direct contacts. This data allows us to calculate the numerator of $\bar{Y}_{M_{j}}=\sum_{i \in\left\{i \mid X_{i, j}=0\right\}} Y_{i, j} / M_{j}$ as $\sum_{\left\{i \mid X_{i}, j=0\right\}} Y_{i, j}=\sum_{i} Y_{i, j}-\sum_{\left\{i \mid X_{i, j}=1\right\}} Y_{i, j}$.

One additional difficulty is that we do not have all the class cards for some of the sections. In those sections, our measure of $\bar{Y}_{M_{j}}$ could be biased in two ways. First, if we calculated the denominator $M_{j}$ by simply subtracting the number of "identified" pre-MBA entrepreneurs from the size of section $j$, we would systematically overestimate the denominator. We correct this potential source of bias by applying the pre-MBA entrepreneurship rate, $\widetilde{N}_{j} /\left(\widetilde{N}_{j}+\widetilde{M}_{j}\right)$ calculated on the sample of available class cards, $\widetilde{N}_{j}+\widetilde{M}_{j}$ to the full section size, $N_{j}+M_{j}$, i. e., $M_{j}=\left(N_{j}+M_{j}\right)\left(1-\frac{\widetilde{N}_{j}}{\widetilde{N}_{j}+\widetilde{M}_{j}}\right)$. Hence, $\bar{Y}_{M_{j}}$ is calculated as

\section{\# of post-MBA entrepreneurs in section $j$ - \# of pre-and-post entrepreneurs in section $j$} section size $\times(1-$ section's pre-MBA entrepreneurship rate $)$

or,

$$
\bar{Y}_{M_{j}}=\frac{\sum_{i} Y_{i, j}-\sum_{\left\{i \mid X_{i}=1\right\}} Y_{i, j}}{\left(N_{j}+M_{j}\right)\left(1-\frac{\widetilde{N}_{j}}{\widetilde{N}_{j}+\widetilde{M}_{j}}\right)}
$$

A second potential source of bias due to missing class cards is that, by failing to account for some pre-MBA entrepreneurs, we might underestimate the number of pre- 
and-post-MBA entrepreneurs, $\sum_{\left\{i \mid X_{i}=1\right\}} Y_{i, j}$, i.e., overestimate the numerator of $\bar{Y}_{M_{j}}$. Relatedly, we might simply miss that a student became an entrepreneur even though he or she (anonymously) indicated entrepreneurship in the placement survey. Both biases would lead us to overestimate the rate of post-not-pre-entrepreneurs. To check the robustness of our results to this potential bias, we re-do each analysis assuming that a set percentage of the students who were entrepreneurs prior to entering the MBA program also chose this career upon graduation. We use $30 \%$ in the results reported in the paper, a rate based on data from the Rock Center survey described below. (We also use other rates and find they had little impact.)

Finally, we collect data on the success of firms established by students while at HBS or within one year of graduation. It is hard to find an objective threshold criterion of "success." For the bulk of the paper we define a successful business as one that, as of October 2007, (a) went public, (b) was acquired for more than $\$ 5$ million, or (c) had in October 2007 or at the time of the sale of the company at least 50 employees or $\$ 5$ million in annual revenues. Only $13 \%$ of the post-MBA entrepreneurs were successful using these criteria. In supplemental analyses, we employ a higher hurdle, requiring that a firm (a) went public, (b) was acquired for more than $\$ 100$ million, or (c) had in October 2007 or at the time of the sale of the company at least $\$ 100$ million in revenues. ${ }^{15}$

We determine this information from three sources. First, we obtained access to the research of the HBS External Relations (Development) Office into its entrepreneurial alumni. This research process intensified in 2006 and 2007, in anticipation of a planned 2008 conference in honor of the institution's $100^{\text {th }}$ anniversary that was intended to bring together its most successful and/or influential entrepreneurial alumni. Second, we also obtained access to the online survey of entrepreneurial alumni conducted by the Rock Center for Entrepreneurship. The survey sought to capture information about students who participated in the above-mentioned business plan contest, which has been offered to second-year students since 1997, as well as others known to have undertaken early-career entrepreneurial ventures. The survey used a "viral" approach, whereby known entrepreneurs were asked to identify other entrepreneurs among their classmates, and

\footnotetext{
${ }^{15}$ While we would have liked to determine the success as of a set time after graduation (e.g., three years after degree completion), this information proved infeasible to gather.
} 
encourage them to complete the survey. ${ }^{16}$ Third, we conducted interviews with the faculty in the HBS Entrepreneurial Management unit. These faculty members are often intimately involved with alumni ventures, whether as sponsors of the independent studies where the initial business plans are drawn up or as directors, advisory board members, or investors in subsequently established ventures. Even without a formal role, these faculty members often stay in touch with alumni entrepreneurs. As a result, they have extensive knowledge about the performance of these ventures. In some cases, none of the three sources revealed the exact specifics regarding the revenues, public status, or acquisitions of our sample firms. In these cases, we consulted a wide variety of business databases, such as CorpTech, EDGAR, Factiva, and Orbis. We also contacted entrepreneurs directly to obtain this information on a confidential basis.

After compiling this information on individual ventures, we again aggregate it on the section level. We compute the share of the class who became entrepreneurs after graduation, as well as those who became successful entrepreneurs, both for the entire graduating class and only for those who were not entrepreneurs prior to graduation. (The latter is the dependent variable in our regression analyses.)

Figure 2C summarizes some key patterns of the outcomes data. (Because we have placement data for virtually all students, we report the data here for all sections.) Entrepreneurial activities vary over time, with the peak in entrepreneurial entry occurring around 2000 . More than $10 \%$ of the class began entrepreneurial ventures upon graduating in 2000. The rate of successful entrepreneurship is low, even when using the first, less demanding definition of successful entrepreneurship. The temporal pattern of success is less pronounced, but, generally, the years that saw the greatest number of successful entrepreneurs were earlier (suggesting that less suited students may have been drawn into entrepreneurship by their predecessors' successes).

\section{Empirical Analysis}

Our analysis proceeds in several steps. First, we perform several tests of stratification and (conditional) randomization in section assignment. Then, we present our

\footnotetext{
${ }^{16}$ Alumni were initially contacted via e-mail in January 2005. Non-respondents were contacted three times via e-mail and telephone. Overall, $41 \%$ of all contacted students participated. This rate is consistent with or above the level of responses typical in social science studies of this cohort (Baruch [1999]).
} 
main result, the analysis of peer effects on the rate of students in each section becoming entrepreneurs, as well as differential peer effects on the rate of successful versus unsuccessful entrepreneurs. Finally, we explore possible channels for entrepreneurial peer effects, including an effect of prior entrepreneurs' own previous success or failure and an effect on enrollment in elective entrepreneurship classes.

\section{IV.A. Test of Stratification and Randomization}

We saw already that the distribution of pre-MBA entrepreneurs across sections appear to be random (e.g., in Appendix Figure 1). We now compare the distribution of the students without an entrepreneurial background in sections with more (above median) and fewer (below median) pre-MBA entrepreneurs. We test whether the students display significant differences in any of their demographics or other characteristics. Here, differently from our main analysis, we include all students in a section and compare those with and without prior entrepreneurial experience. The results of all 69 variables are presented in Appendix Table A1. Out of all job-related characteristics (last job in consulting, investment banking, private equity), demographics (gender, US citizenship, children, partner, age range), our risk score measure, and education (attendance of an Ivy League or Ivy League Plus college, and major), we find that seven sets of differences are significant at the five-percent confidence level: sections with more entrepreneurs are less likely to have students who worked in non-computer-related high-tech $(0.7 \%$ versus $1.3 \%$ ), who attended elite schools (22.9\% versus $25.3 \%$ for Ivy League and $32.9 \%$ versus $35.7 \%$ for Ivy League plus), who majored in history (3.1\% versus $4.3 \%)$, and who had a function in strategic planning $(3.7 \%$ versus $4.8 \%)$ or in human resources $(0.1 \%$ versus $0.4 \%)$ and are more likely to have students who had a function in medical services $(0.7 \%$ versus $0.3 \%$ ). Many of the differences, however, are in categories with a very small number of positive respondents, and the differences range only from 0.3 to 1.3 percent. Another seven variables differ at the ten-percent level, with the differences ranging from 0.4 to 1.8 percent.

We aim to control for these differences in our main analysis. Given that we have sixty sections with seventy class cards, we cannot use all 69 characteristics (nor even the 14 significant characteristics). In order to identify the most relevant variables, we used two forward-selection procedures, reported in Table III. First, we start with a number of 
variables that are commonly viewed as being particularly influential in determining the propensity of students to become entrepreneurs: having consulting, investment banking, and private equity backgrounds, gender, nationality, the presence of partners and children, attendance at an Ivy League or Ivy Plus college, risk appetite, and year of graduation. We then conduct a forward stepwise selection to identify which additional student characteristics have significant explanatory power (at the 5\% level) in predicting the share of pre-MBA entrepreneurs in a section using a linear regression framework and controlling for year effects. This led to the identification of three additional independent variables - students having a background in agriculture and health care, and those majoring in engineering. Second, we used a forward step-wise approach, with only year dummies preset, and include all additional variables significant at the 5\% level. In this case, we identify five variables in addition to the year dummies. (We use both sets of control variables in our analyses. We report the analyses with the first set of variables in the main tables. All replications with the second set of independent variables are available from the authors.)

Overall, these results suggest that a relatively small number of demographic and other characteristics have significant explanatory power and help identify the non-random variables to be controlled for in the final regression analysis.

\section{IV.B. Univariate Comparisons}

We begin by analyzing the basic relationship between the representation of students with previous entrepreneurial experience in a given section and the rates of total and successful post-MBA entrepreneurship.

First, we review the patterns graphically. Figure $3 \mathrm{~A}$ looks at the relationship between the share of pre-MBA entrepreneurs in the section and the share of total postMBA entrepreneurs (without prior entrepreneurial experience). ${ }^{17}$ The panel suggests that sections with more prior entrepreneurs have considerably less variation in the share of entrepreneurs after graduation. Moreover, the sections with few pre-MBA entrepreneurs have on average higher rates of post-MBA entrepreneurs.

Figure $3 \mathrm{~B}$ looks only at the share of unsuccessful post-MBA entrepreneurs. Here

\footnotetext{
${ }^{17}$ This is calculated by subtracting out the number of pre-and-post-MBA entrepreneurs (the first corrective methodology described in Section III).
} 
the pattern is more pronounced: there appears to be a negative relation between the share of pre- and the share of post-MBA entrepreneurs. Meanwhile, the pattern in Figure 3C, which looks at the share of successful post-MBA entrepreneurs, is less pronounced and relatively flat, with the exception of one section with a high number of successful entrepreneurs and a high normalized pre-MBA entrepreneurship rate. Certainly, no sign of a negative relationship, as identified in the other two panels, appears here.

Table IV examines the correlation coefficients between various characteristics of the sections and the share of students without an entrepreneurial background who became entrepreneurs after finishing the program. We see that those sections which had relatively more males, U.S. citizens, and students with children were more likely to have higher rates of entrepreneurship. (Again, all variables are computed using just the students who were not pre-MBA entrepreneurs.) Both venture capital funding and IPO activity in the year of graduation are highly correlated with post-MBA entrepreneurship. Finally, the correlation with the section share of students with prior entrepreneurial experience provides suggestive evidence speaking to our main research question: Consistent with the pattern observed in Figure 3, there is a statistically significant, negative relationship between the share of students in a section who were entrepreneurs prior to business school and those who were not prior entrepreneurs but began ventures after their MBA.

The correlations with successful entrepreneurship are much weaker. The only significant correlates are the measures of entrepreneurial finance activity in the year of graduation, and even these are not consistently significant at the five-percent confidence level. The relationship between the share of pre-MBA entrepreneurs and the share of the post-not-pre-MBA entrepreneurs in the section becoming successful entrepreneurs is positive but insignificant. One reason for the lack of significance is the very small sample of successful post-MBA entrepreneurs. If we compare the fraction of successful entrepreneurs (among all post-not-pre entrepreneurs ${ }^{18}$ ) in sections with above and belowmedian numbers of pre-MBA entrepreneurs, $18.0 \%$ versus $7.5 \%$, the difference is not significant ( $\mathrm{p}$-value $=17.1 \%$ ), but economically large.

These patterns are, of course, simply suggestive. Our main analysis, in the next

\footnotetext{
${ }^{18}$ The success rate is not calculated for the sections with no post-MBA entrepreneurship.
} 
subsection, controls for a number of features of the sections simultaneously.

\section{IV.C. Regression Analyses}

We now turn to the regression analyses of post-MBA entrepreneurship. The units of observation are section-years. The main dependent variable is the share of the section without prior entrepreneurial background who became entrepreneurs immediately after graduation (either overall or divided into successful and unsuccessful). As derived in Section II.D, we control for the characteristics of these same students. That is, the independent variables in the regressions are calculated using only those students who were not entrepreneurs prior to entering business school (with the exception, of course, of the share of prior entrepreneurs in the section).

Table $\mathrm{V}$ presents the first main result, the analysis of entrepreneurial peer effects on the propensity of students who were not entrepreneurs prior to entering business school but to become entrepreneurs afterwards. Because the left-hand side variable is censored at zero, we first estimate a Tobit specification. However, since the Tobit specification does not allow us to employ year dummy variables (the estimates do not converge), we use the volume of venture financing and IPOs as controls. Alternatively, we show OLS specifications with the inclusion of year dummies. In those specifications we can also add pairwise interactions between significant explanatory variables as additional controls. The variables we use for the interactions are the share of section that is male, that are U.S. citizens, with a partner, and with investment banking background.

As discussed in Section III, we use the two methods to correct the aggregate post-

MBA entrepreneurship rate for prior entrepreneurial experience: the first three regressions subtract out the number of identified pre-and-post-MBA entrepreneurs, while the last three subtract an average post-MBA entrepreneurship rate of 30\% among preMBA entrepreneurs.

All regressions confirm the pattern found in the raw data: The coefficient on the share of the section with an entrepreneurial background is always negative. The effect is not only statistically significant, but economically meaningful. In the first OLS regression, a one standard deviation increase in the pre-MBA entrepreneurship rate translates into a decrease of $26.5 \%$ in the predicted rate of entrepreneurship after business school: the share of post-not-pre entrepreneurs drops by more than one percentage point 
$(-0.35 \times 0.029)$, from $3.9 \%$ to $2.9 \%$. The second set of regressions suggests a decline of an even larger magnitude (33.3 percent).

In addition to our main result, we observe several interesting patterns. The share of students with a private equity background is positive but insignificant (after the inclusion of year dummies). The difference in sign, relative to the pre-MBA entrepreneurship coefficient estimate, may reflect the fact that this category is dominated by students who have worked for buyout firms that have little exposure to young firms, rather than for venture capitalists. We also see that the coefficient on the share of the section that is male is always positive and typically statistically significant, while the share that has a partner is always negatively and (at least marginally) significant. The coefficient on the mean risk tolerance of the section is generally insignificant. Finally, more entrepreneurial activity in the economy is associated with periods of more venture activity. When we employ class dummies, those for 1999 and 2000 have the greatest magnitude and significance. When we employ the venture and IPO dummies, the measure of the level of venture activity in the year of graduation is consistently positive and significant at the one-percent level.

We then distinguish between the rates of unsuccessful and successful post-MBA entrepreneurs. We define the rate of unsuccessful entrepreneurship as the difference between the total rate of entrepreneurship and the successful entrepreneurship rate in each section. ${ }^{19}$

Table VI presents regressions with the same set of specifications as in the previous table. The dependent variable is the share of post-MBA entrepreneurs who were not previously entrepreneurs and whose ventures started after graduating ultimately failed (in Panel A) or whose ventures were successful (in Panel B).

The results of the regressions explaining unsuccessful entrepreneurship (in Panel A) are very similar to those for overall entrepreneurship in Table V. The share of the section with prior entrepreneurial background is significantly negatively associated with unsuccessful post-MBA entrepreneurship among their peers. The coefficients are almost

\footnotetext{
${ }^{19}$ While we believe that we identified a virtually comprehensive list of successful HBS entrepreneurs from the classes in our sample, a similar approach would not have worked for unsuccessful entrepreneurs. Unsuccessful ventures are frequently much less visible, and participants may not be willing to disclose them (e.g., in response to a survey request) after the failure.
} 
identical to those in the baseline analysis. Also the other independent variables are quite similar in terms of significance and size.

The estimation results imply that the economic magnitude of the entrepreneurial peer effect is even larger for unsuccessful entrepreneurs than in the baseline estimation, given that the rate of unsuccessful entrepreneurs is slightly lower (3.6\%). Using again the coefficient estimate from the first OLS regression, a one standard deviation increase in the pre-MBA entrepreneurship rate translates into a decrease of $29.8 \%$ (more than one percentage point [-0.36 $\times 0.029]$ out of $3.6 \%$ unsuccessful post-not-pre entrepreneurs) in the predicted rate of (ultimately) unsuccessful entrepreneurship after business school. The rate is $35.6 \%$ using the second set of regressions.

The results of the regressions explaining successful entrepreneurship (in Panel B), instead, are very different: The coefficient on the share of pre-MBA entrepreneurs is always positive. The coefficients are much smaller, ranging from 0.03 to 0.12 , while the standard errors remain similar to those in Panel B. As a result, the coefficients are never statistically significant. Nor are any of the other variables that are important in the Table $\mathrm{V}$ regressions consistently significant. The goodness of fit is also considerably lower. Given the low average rate of successful entrepreneurs $(0.3 \%$ of those without prior experience) and left-censoring, the representation of successful entrepreneurs is much more difficult to predict.

In Panel C, we report the results of formal tests of whether the coefficients on the variables measuring the entrepreneurial background of the section are the same in the unsuccessful and successful regressions in Panel A and B. We do this by estimating a pooled regression and then performing a t-test of the null hypothesis that the coefficients on the pre-MBA entrepreneurial share variable are not different in the successful and unsuccessful entrepreneurship regressions. (That is, we examine the significance of the interaction between the pre-MBA entrepreneur share and the dummy variable denoting successful outcomes.) We also undertake an F-test comparing all coefficients in the two regressions. The null hypothesis of no difference is always rejected at the one-percent confidence level.

Thus, the presence of peers who have had entrepreneurial experience tends to deter students without an entrepreneurial background from undertaking unsuccessful 
ventures, but does not deter those students who will launch successful ventures. Indeed, entrepreneurial peers may even have a slightly positive effect on would-be successful entrepreneurs.

One concern with these latter findings is the potential limitations of our success measure. For example, our measure of success classifies firms such as Guru.com, an online marketplace for freelance talent, as successful since it was sold for approximately $\$ 5$ million to rival Unicru in 2002. Whether any of the key parties associated with the firm regarded this as a success is doubtful, given that Guru.com raised over $\$ 62$ million in venture capital financing in 1999 and $2000 .^{20}$ In order to address this concern, we repeat the above analyses using our alternative and more restrictive measure of success, based on the $\$ 100$ million cutoff defined above. Table VII, Columns 1 and 2, shows results akin to those reported in the specifications of Column 2 of Table VI, in Panel A and Panel B. The coefficient estimates closely resemble those using our original success measure, not only in terms of sign and significance but also in actual magnitude. Moreover, the coefficients on the share of pre-MBA entrepreneurs in the two reported regressions (not super-successful versus super-successful) are significantly different at the one-percent confidence level.

Another concern is related to the HBS class of 2000, which as Figure 2C revealed, had an extraordinary high post-MBA entrepreneurship rate. In an unreported analysis, we reran the regressions without the observations from the class of 2000 . The results were little changed.

\section{IV.D. Interpretation and Robustness}

As noted in the introduction, we can offer a variety of explanations for the results seen above. A first channel for intra-section learning is direct interaction with pre-MBA entrepreneurs and their counsel about what constitutes a good business idea. Intra-section learning of this type is most consistent with the views offered by many alumni and students, who argue that certain individuals who were entrepreneurs prior to business school play a critical if informal knowledge dissemination role: Would-be entrepreneurs

\footnotetext{
${ }^{20}$ The information on Guru.com was obtained from http://www.venturexpert.com (accessed November 17, 2007), Factiva, and other on-line sources.
} 
approach these individuals, and receive help evaluating their potential business plans and understanding their strengths and weaknesses. While others in the section may have the same analytical skills, the personal experience of prior entrepreneurs gives them a credibility others do not have.

A second interpretation is that the presence and reports of former entrepreneurs simply discourage would-be entrepreneurs and lead them to abandon or at least postpone their plan to start a company. This explanation is particularly plausible if the entrepreneurial peers had negative experiences, given that we estimated the peer effect to be significantly negative.

A third alternative is that entrepreneurial peers drive others to take additional entrepreneurship classes as electives, which may lead them to subsequently make better decisions about pursuing new ventures.

The third hypothesis suggests that there should be a positive relationship between the presence of prior entrepreneurs in a section and the enrollment in elective entrepreneurship classes. To examine this prediction, we use our additional data on enrollment in elective entrepreneurship classes, i.e., second-year classes that fell under the sponsorship of the Entrepreneurial Management unit. (Recall that all second-year classes during this period were electives.) We employ the share of entrepreneurship classes that the students without an entrepreneurial background took in their second year as the new outcome variable and repeat the prior regression analyses. Column 3 of Table VII displays the regression analysis that mirrors Column 2 of Table V. None of the coefficient estimates are significant at the five-percent confidence level. Even among the control variables, the sole marginally significant coefficient estimate (for gender) varies depending on the regression specification. (The exceptions are two time dummies: the classes of 2000 and 2001 had the greatest enrollment in entrepreneurship classes.) Most importantly, the impact of peers with an entrepreneurial background is always positive, but very weak and never significant. ${ }^{21}$ Hence, we find no support for the explanation that entrepreneurial peers induce others to take entrepreneurship classes.

The finding on enrollment in entrepreneurship classes also does not lend support

\footnotetext{
${ }^{21}$ Because the number of electives shifted over time, and the number of sections with seventy or more class cards is not evenly distributed, we repeated these analyses for all sections and for the set of the sections with forty or more class cards. We use weighted and unweighted data. The results are the same.
} 
to the second explanation, i.e., the interpretation that entrepreneurial peers dampen interest in entrepreneurship. Under this interpretation, we would have expected a negative coefficient. Also, as mentioned above, the second interpretation would be more plausible if pre-MBA entrepreneurs tend to be failed entrepreneurs, whose previous experiences dampen the general enthusiasm about entrepreneurship among their peers. However, as we saw already, empirically many pre-MBA entrepreneurs in our sample have been quite successful, with some even having sold companies for tens of millions of dollars.

But even if we rule out a mere selection effect (of peers with particularly negative past experiences), it is still plausible that the outcome of prior entrepreneurial ventures colors the influence that pre-MBA entrepreneurs exert on the entrepreneurial ambitions of their section-mates: A successful entrepreneur may be more encouraging, and a failed entrepreneur may be more discouraging.

We test this hypothesis using our hand-collected data on the success or failure of prior ventures of MBA students (pre-MBA entrepreneurs). Table VIII presents the same regression specifications as Table VI, but using the share of pre-MBA entrepreneurs split into those who were successful pre-MBA and those who failed. Similar to the classification of unsuccessful and successful post-MBA entrepreneurs, we define the rate of unsuccessful pre-MBA entrepreneurs in each section as the difference between the total rate and the rate of successful pre-MBA entrepreneurs. Panel A tests how the presence of successful and unsuccessful pre-MBA entrepreneurs affects the rate of unsuccessful post-MBA entrepreneurs. All coefficient estimates are negative and similar in magnitude to our previous estimations, though estimated less precisely. The loss of significance is not surprisingly given that we are splitting the already small number of pre-MBA entrepreneurs into two groups. Panel B shows the effect on successful entrepreneurs. As in Table VI.B, the goodness of fit is considerably lower, and none of the coefficient estimates of interest is significant. Even directionally, it is not the case that successful pre-MBA entrepreneurs always have a more positive or less negative effect on their peers than unsuccessful pre-MBA entrepreneurs. Hence, we have no evidence for the hypothesis that the specific prior experience of entrepreneurial peers is central in explaining the results, though it is possible that the lack of significant results reflects the lack of power. 
Overall, the additional analyses of enrollment in entrepreneurship classes and of the influence of prior success and failure suggest that the second and third explanations are somewhat less plausible than the first explanation, i.e., the hypothesis that the estimated peer effect reflects learning via direct interaction and feedback on business ideas. However, providing direct evidence for this learning channel is difficult, given that there is no historical record of specific student interactions.

As a final piece of evidence, we examine the variance, rather than the mean rate of entrepreneurship. As hypothesized above, sections with fewer students with an entrepreneurial background are likely to display a greater variance in their post-MBA entrepreneurship rates, particularly in the share of unsuccessful entrepreneurs. If intrasection learning relies on direct interaction, then, the fewer pre-MBA entrepreneurs are in a section, the less likely it is that one of them finds the flaw in the business plan.

Table IX reports the variance in the rate of post-MBA entrepreneurship separately for sections with a below-median and with an above-median share of pre-MBA entrepreneurs. We find that sections with more entrepreneurs have less variance in the overall entrepreneurship rate, a pattern entirely driven by the unsuccessful entrepreneurs. At least part of the observed $44 \%$ reduction in variance may be explained as mechanistic and due to the reduction in the likelihood to become entrepreneur when many pre-MBA entrepreneurs are present. The remainder, however, points to the channel of intra-section learning: if the impact of pre-MBA entrepreneurs comes from their interaction with aspiring entrepreneurs among their section-mates, the effect will be noisier when there are fewer pre-MBA entrepreneurs present and, hence, interaction and productive feedback are less likely. With a large enough number of entrepreneurs present, instead, one of them will be critical and experienced enough to detect the "flaw" in a business plan.

\section{Conclusions}

This paper studies a topic of increasing scholarly and practical interest, the impact of peer effects on the decision to become an entrepreneur. We examine the decision to undertake entrepreneurial activities among recent graduates of the Harvard MBA program. This setting is an attractive one for a study of these issues due to the exogenous 
assignment of students to sections, the ability to distinguish firm outcomes, and the potentially high economic impact of these ventures.

We find that a higher share of students with an entrepreneurial background in a given section leads to lower rates of entrepreneurship among students without an entrepreneurial background. This effect is driven by the rate of (ultimately) unsuccessful entrepreneurs: students in sections with more pre-MBA entrepreneurs are less likely to start unsuccessful ventures. The relationship between the share of pre-MBA entrepreneurs and (ultimately) successful post-MBA entrepreneurs is considerably weaker, but appears to be slightly positive. The presence of former entrepreneurs does not affect enrollment in entrepreneurship classes by section-mates in the second year, and whether former entrepreneurs were successful or unsuccessful themselves also does not affect the results. Finally, sections with few prior entrepreneurs have a considerably higher variance in their rates of unsuccessful post-MBA entrepreneurship. We argue that these results are consistent with intra-section learning, where the close ties between students in a section lead to an enhanced understanding of the merits of proposed business ideas.

We highlight two avenues for future research. First, this paper suggests a richer role for peer effects in entrepreneurship than what has been described in the prior literature. Most of the empirical studies of peer effects in entrepreneurship, for instance, have implicitly assumed a "contagion effect," where the decision of one individual to begin a firm leads others to do so likewise. This analysis suggests that there are more subtle dynamics are at work, with specific feedback on business ideas might play a larger role. Understanding how these effects work in more detail would be very worthwhile.

A second avenue for future research is exploiting section assignments at HBS to look at other phenomena. The differing educational, national, religious, and experiential mixtures of the various sections should make this a fertile testing ground for a variety of network and peer effects. Shue's [2011] analysis of executive compensation and acquisition strategies of companies headed by HBS graduates represents one such important analysis, and points to the breadth of research topic possible with these data. 


\section{References}

American Sports Data, 2005, A Comprehensive Study of Sports Injuries in the U.S., Cortlandt Manor, NY, American Sports Data.

Arabsheibani, Gholamreza, David de Meza, John Maloney, and Bernard Pearson, 2000, And a vision appeared unto them of a great profit: Evidence of self-deception among the unemployed, Economic Letters 67, 35-41.

Baruch, Yehuda, 1999, Response Rates in Academic Studies-A Comparative Analysis, Berlin, Springer Science+Business Media.

Baumol, William J., 1990, Entrepreneurship: Productive, unproductive, and destructive, Journal of Political Economy 98, 893-921.

Bernardo, Antonio, and Ivo Welch, 2001, On the evolution of overconfidence and entrepreneurship, Journal of Economics \& Management Strategy 10, 301-30.

Bhide, Amar, 2000. The Origins and Evolution of New Businesses, New York, Oxford.

Broughton, Philip, D., 2008, Ahead of the Curve: Two Years at Harvard Business School, New York, Penguin.

Camerer, Colin, and Dan Lovallo, 1999, Overconfidence and excess entry: An experimental approach, American Economic Review 89, 306-318.

Cruikshank, Jeffrey L., 2005, Shaping the Waves: A History of Entrepreneurship at Harvard Business School, Boston, Harvard Business School Publishing.

Davis, Steven J., John C. Haltiwanger, and Scott Schuh, Job Creation and Destruction, Cambridge, MIT Press.

De Meza, David, and Clive Southey, 1996, The borrower's curse: Optimism, finance, and entrepreneurship, Economic Journal 106, 375-386.

Djankov, Simeon, Rafael La Porta, Florencio Lopez-de-Silanes, and Andrei Shleifer, 2002, The regulation of entry, Quarterly Journal of Economics 117, 1-37.

Duflo, Esther, and Emmanuel Saez, 2002, Participation and investment decisions in a retirement plan: The influence of colleagues' choices, Journal of Public Economics 85, 121-148.

Duflo, Esther, and Emmanuel Saez, 2003. The role of information and social interactions in retirement plan decisions: Evidence from a randomized experiment, Quarterly Journal of Economics 118, 815-842. 
Eesley, Charles, David Hsu, and Edward Roberts, 2007, Entrepreneurs from technologybased universities: Evidence from MIT, Research Policy 36, 768-788.

Evans, David S., and Linda S. Leighton, 1989, Some empirical aspects of entrepreneurship, American Economic Review 79, 519-535.

Ewing, David W., 1990, Inside Harvard Business School: Strategies and Lessons of America's Leading School of Business, New York, Times Books.

Giannetti, Mariassunta, and Andrei Simonov, 2009, Social interactions and entrepreneurial activity, Journal of Economics and Management Strategy, 18, 665-709.

Gompers, Paul A., Anna Kovner, Josh Lerner, and David Scharfstein, 2008, Venture capital investment cycles: The impact of public markets, Journal of Financial Economics, 87, 1-23.

Gompers, Paul A., Josh Lerner, and David Scharfstein, 2005, Entrepreneurial spawning: Public corporations and the genesis of new ventures, 1986 to 1999, Journal of Finance, $60,577-614$.

Jovanovic, Boyan, 1982, Selection and the evolution of industry, Econometrica 50, 649670.

Kanniainen, Vesa, and Christian Keuschnigg, 2004, Venture Capital, Entrepreneurship, and Public Policy, Cambridge, Massachusetts, MIT Press.

Katz, Jerome A., 2004, Survey of Endowed Positions in Entrepreneurship and Related Fields in the United States, St Louis, Missouri, J. A. Katz and Associates.

Kremer, Michael and Dan Levy, 2008, Peer effects and alcohol use among college students, Journal of Economic Perspectives 22 (Summer), 189-206.

Landier, Augustin, and David Thesmar, 2009, Financial contracting with optimistic entrepreneurs: Theory and evidence, Review of Financial Studies 22,117-150.

Lazear, Edward P., 2005, Entrepreneurship, Journal of Labor Economics 23, 649-680.

Manski, Charles F., 1993, Identification of Endogenous Social Effects: The Reflection Problem, Review of Economic Studies 60, 531-542.

Murphy, Kevin M., Andrei Shleifer, and Robert W. Vishny, 1991, The allocation of talent: Implications for growth, Quarterly Journal of Economics 106, 503-530.

Nanda, Ramana, and Jesper Sorensen, 2010, Workplace peer effects and entrepreneurship, Management Science, forthcoming. 
National Venture Capital Association, 2005, 2005 Venture Capital Yearbook, Newark, New Jersey, Venture Economics.

Orth, Charles D., III, 1963, Social Structure and Learning Climate: The First Year at the Harvard Business School, Boston, Division of Research, Graduate School of Business Administration, Harvard University.

Parker, Simon C., 2004, The Economics of Self-Employment and Entrepreneurship, New York, Cambridge University Press.

Sacerdote, Bruce, 2001, Peer effects with random assignment: Results for Dartmouth roommates, Quarterly Journal of Economics 116, 681-704.

Shue, Kelly, 2011, Executive networks and firm policies: Evidence from the random assignment of MBA peers, Unpublished working paper, Harvard University. 
Figure 1. Macroeconomic Conditions over Time
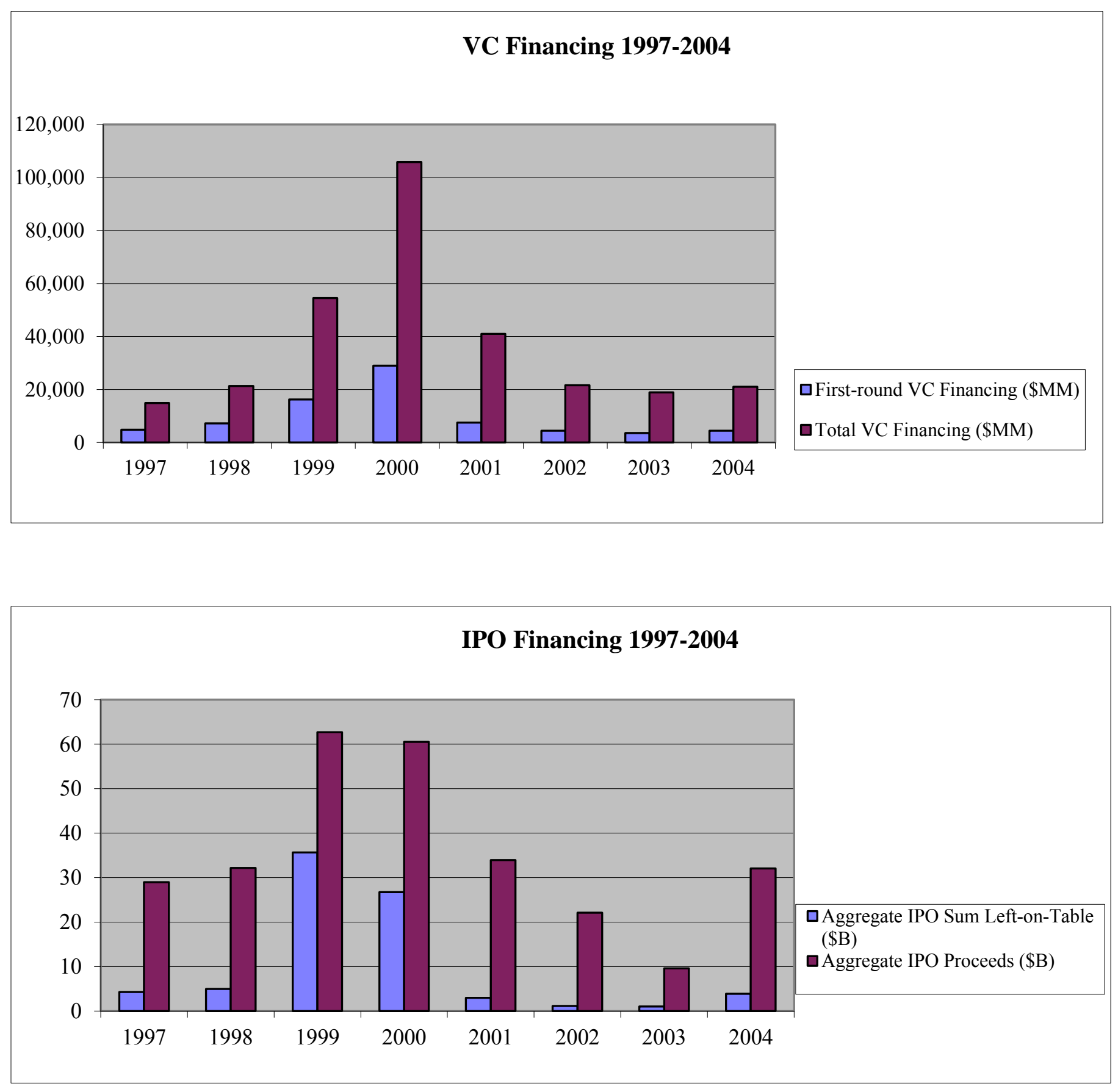
Figure 2. Variation in Entrepreneurial Activity

Figure 2A. Pre-MBA Entrepreneurship Across Sections

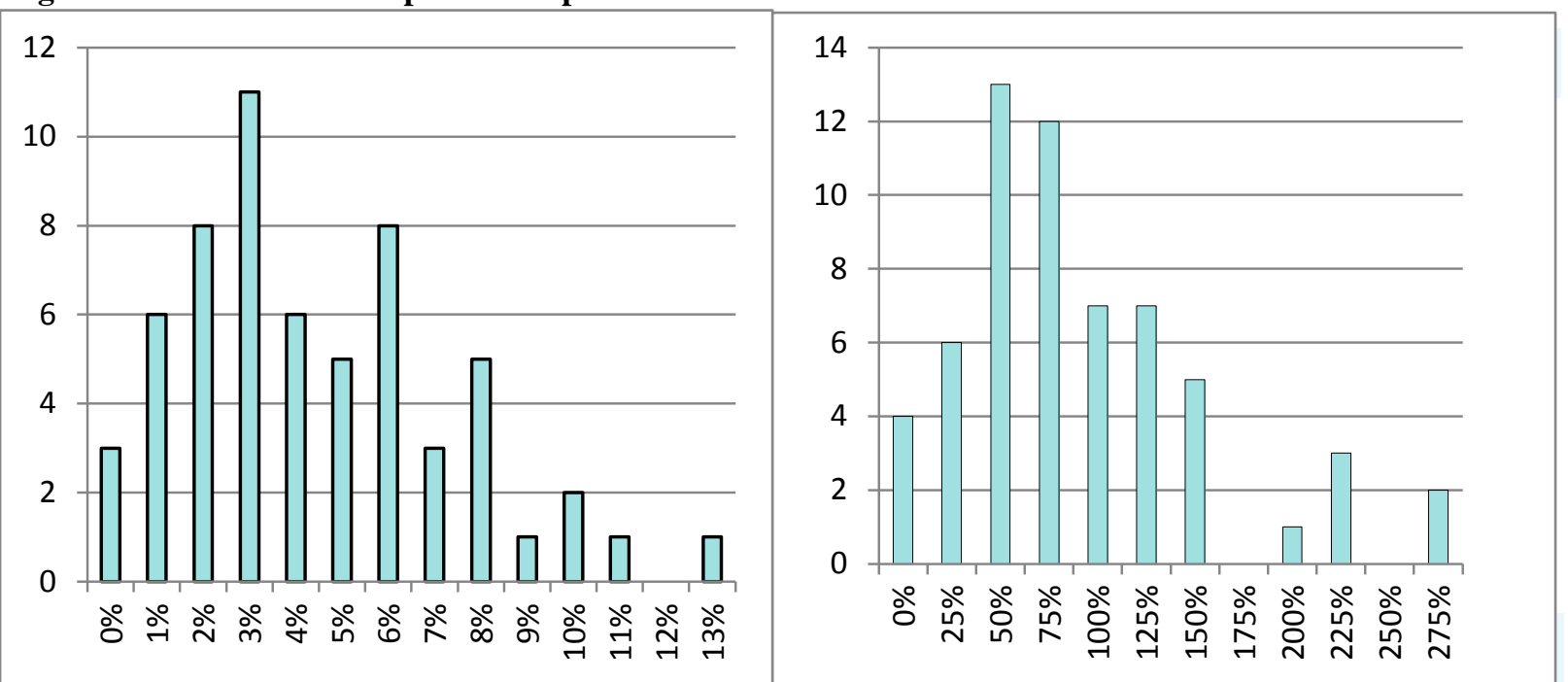

Notes. The left graph shows the histogram of the fraction of students (in percent) with entrepreneurship experience prior to entering the MBA program (relative to section size). The right graph shows the histogram of the number of entrepreneurs normalized by the number of class cards available for the section, divided by the average rate in the same year across sections. The sample contains the 60 sections with 70 or more available class cards.

Figure 2B. Pre-MBA Entrepreneurship Over Time

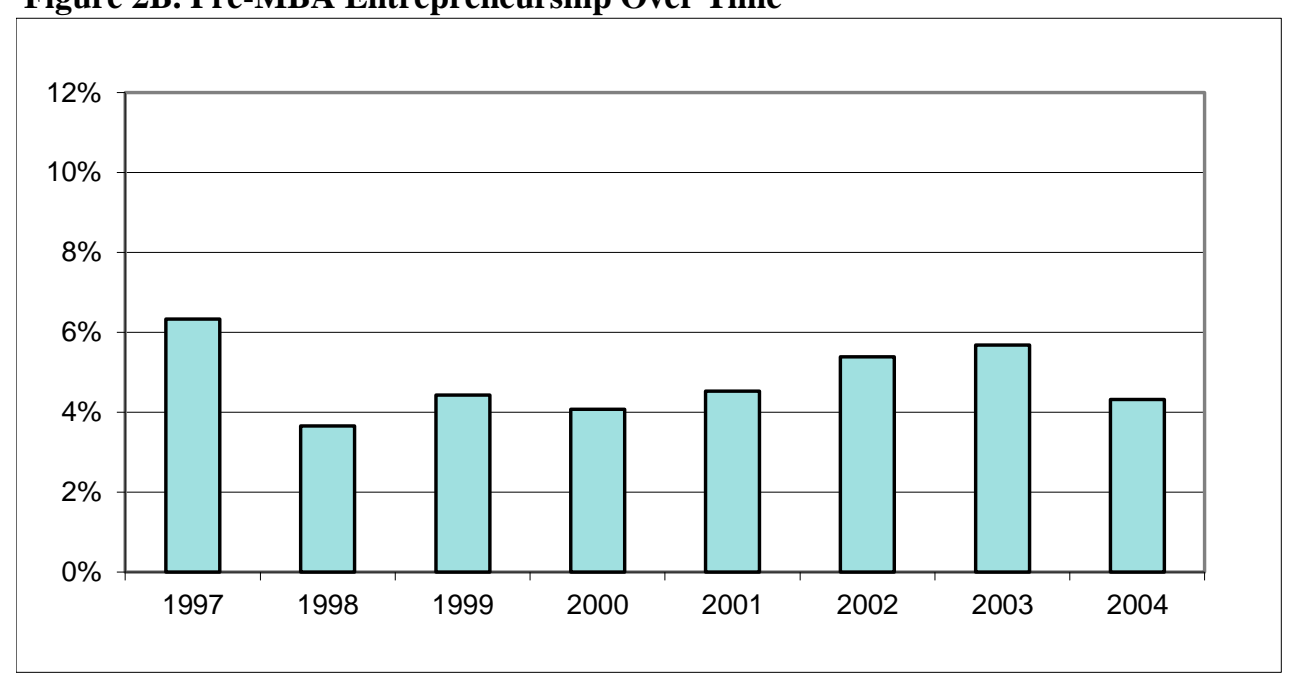

Notes. The graph shows rates of students with entrepreneurship experience prior to entering the MBA program. The sample contains the 60 sections with 70 or more available class cards.

Figure 2C. Post-MBA Entrepreneurship

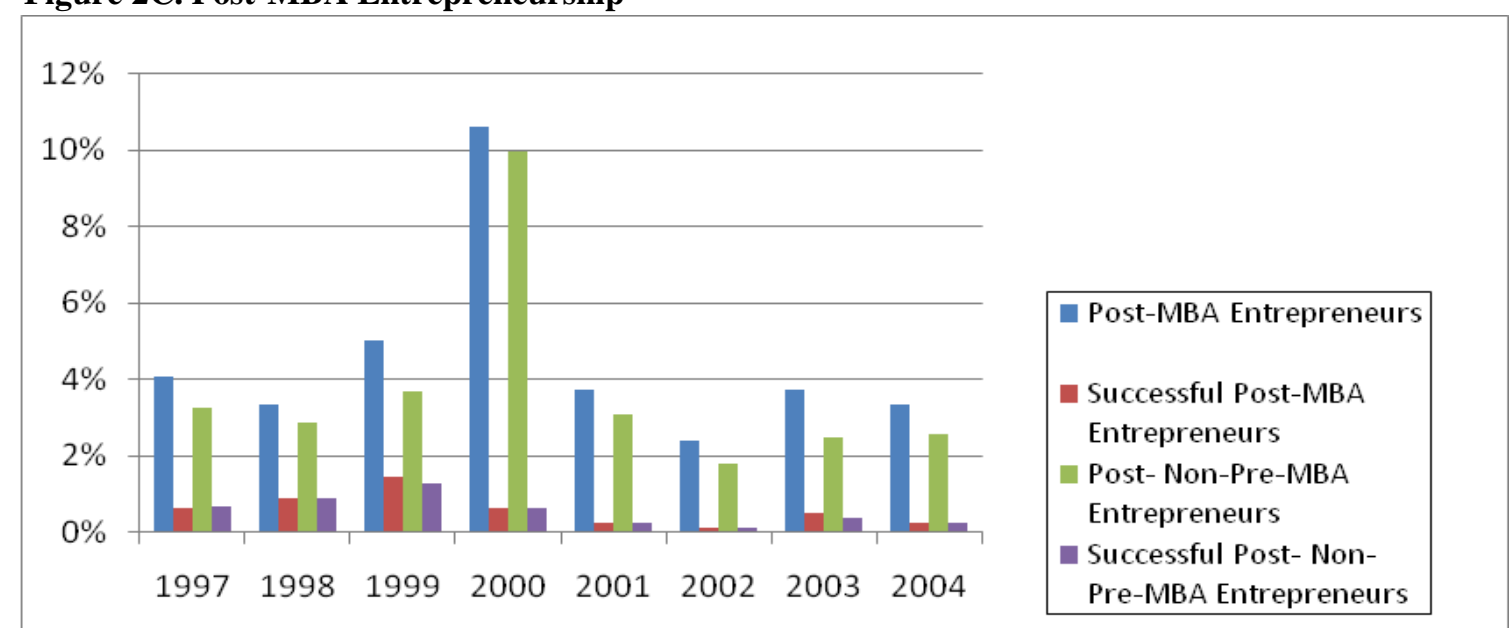

Notes. The graph shows the rate of post-HBS entrepreneurship and the rate of successful post-HBS entrepreneurship for all graduates of the MBA program (two leftmost bars in each year) and the same two rates for students who were not entrepreneurs prior to entering the MBA program (two rightmost bars in each year). 


\section{Figure 3. Relationship between Pre- and Post-MBA Entrepreneurship}

Panel A. All Post-MBA Entrepreneurs

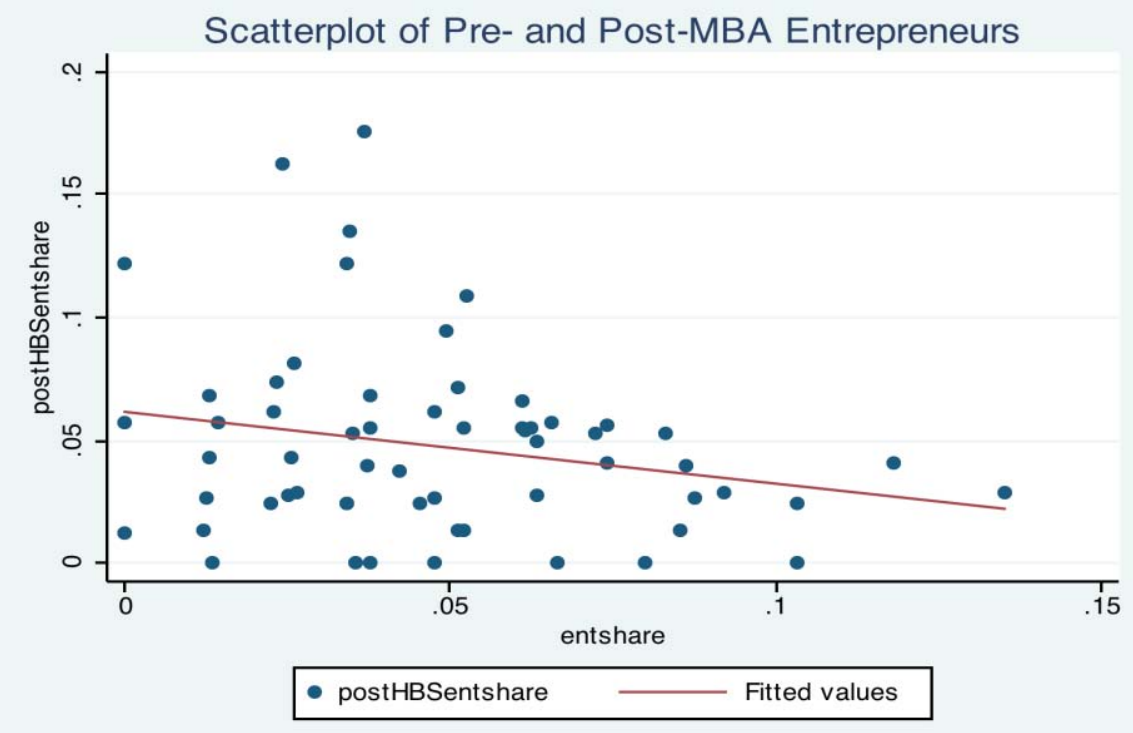

Panel B. Unsuccessful Post-MBA Entrepreneurs

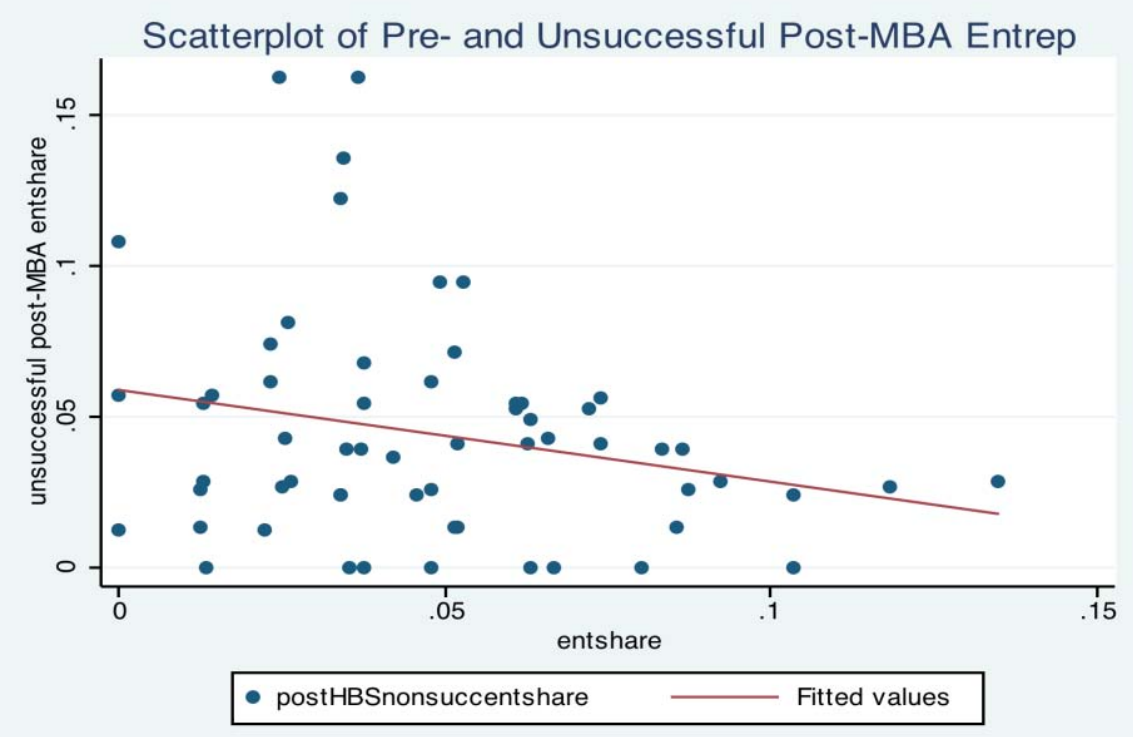

Panel C. Successful Post-MBA Entrepreneurs

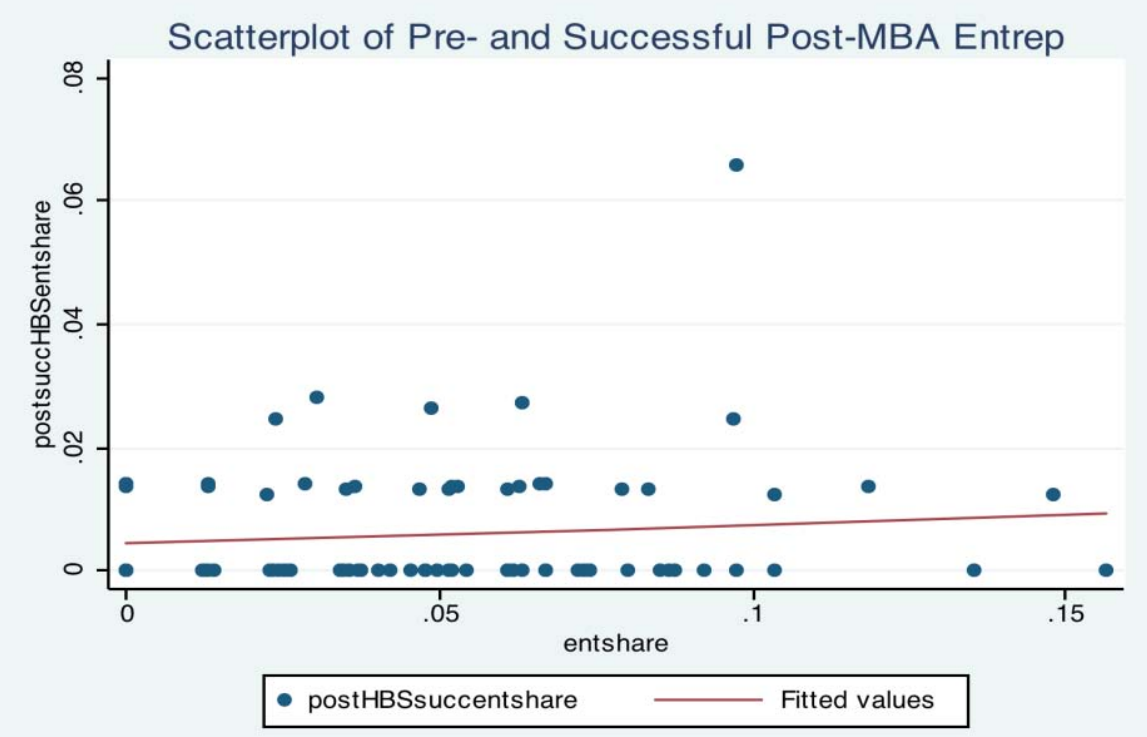

Notes. In all three panels, the sample consists of all sections with at least 70 class cards. 
Table I. Background Variables

\begin{tabular}{|c|c|c|c|c|c|c|c|c|}
\hline & \multicolumn{8}{|c|}{ Class of ... } \\
\hline & 1997 & 1998 & 1999 & 2000 & 2001 & 2002 & 2003 & 2004 \\
\hline MBA Enrollment & 898 & 913 & 903 & 880 & 865 & 917 & 898 & 898 \\
\hline MBA Applications & 6,973 & 8,053 & 7,496 & 8,061 & 8,476 & 8,124 & 8,893 & 10,382 \\
\hline \multicolumn{9}{|l|}{ Profile } \\
\hline Female & $27 \%$ & $24 \%$ & $29 \%$ & $30 \%$ & $31 \%$ & $33 \%$ & $36 \%$ & $35 \%$ \\
\hline Minorities & $19 \%$ & $18 \%$ & $18 \%$ & $19 \%$ & $18 \%$ & $20 \%$ & $21 \%$ & $25 \%$ \\
\hline International & $24 \%$ & $25 \%$ & $26 \%$ & $26 \%$ & $35 \%$ & $32 \%$ & $33 \%$ & $32 \%$ \\
\hline \multicolumn{9}{|l|}{ Undergraduate Majors } \\
\hline Humanities \& Social Science & $50 \%$ & $46 \%$ & $47 \%$ & $42 \%$ & $41 \%$ & $41 \%$ & $45 \%$ & $40 \%$ \\
\hline Engineering \& Sciences & $22 \%$ & $26 \%$ & $29 \%$ & $34 \%$ & $31 \%$ & $31 \%$ & $30 \%$ & $32 \%$ \\
\hline Business Administration & $24 \%$ & $25 \%$ & $20 \%$ & $21 \%$ & $24 \%$ & $24 \%$ & $20 \%$ & $20 \%$ \\
\hline Other & $5 \%$ & $3 \%$ & $4 \%$ & $3 \%$ & $4 \%$ & $4 \%$ & $5 \%$ & $8 \%$ \\
\hline Average Section Size & 90 & 83 & 82 & 80 & 79 & 83 & 82 & 90 \\
\hline \multicolumn{9}{|l|}{ IPOs in Graduation Year } \\
\hline Number of IPOs & 432 & 267 & 457 & 346 & 76 & 67 & 62 & 179 \\
\hline Aggregate Proceeds ( $\$$ billion) & 29 & 32 & 63 & 61 & 34 & 22 & 10 & 32 \\
\hline Aggregate Sum Left-on-Table (\$ billion) & 4 & 5 & 36 & 27 & 3 & 1 & 1 & 4 \\
\hline \multicolumn{9}{|l|}{ Venture Financing in Graduation Year } \\
\hline First-Round Financing (\$ million) & 4,844 & 7,199 & 16,201 & 28,979 & 7,512 & 4,452 & 3,577 & 4,438 \\
\hline Total Financing (\$ million) & 14,897 & 21,270 & 54,480 & 105,832 & 40,943 & 21,615 & 18,924 & 20,993 \\
\hline
\end{tabular}


$\underline{\text { Table II. Section Characteristics }}$

\begin{tabular}{|c|c|c|c|c|c|}
\hline Panel A. Full Sample (86 sections) & Mean & Median & St. Dev. & $\begin{array}{r}\text { 10th } \\
\text { Percentile } \\
\end{array}$ & $\begin{array}{r}90 t h \\
\text { Percentile } \\
\end{array}$ \\
\hline 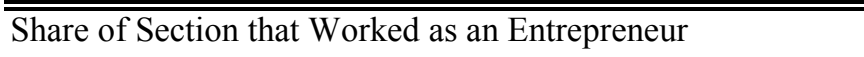 & "5.0\% & 4.7\% & $3.4 \%$ & 0.0\% & $9.8 \%$ \\
\hline$\ldots$ in Consulting & $22.5 \%$ & $22.9 \%$ & $5.4 \%$ & $16.0 \%$ & $28.4 \%$ \\
\hline ... in Investment Banking & $18.7 \%$ & $18.6 \%$ & $5.5 \%$ & $12.8 \%$ & $25.0 \%$ \\
\hline$\ldots$ in Private Equity & $4.6 \%$ & $4.0 \%$ & $3.0 \%$ & $1.1 \%$ & $8.6 \%$ \\
\hline Share of Section that is Male & $70.2 \%$ & $68.5 \%$ & $7.0 \%$ & $63.9 \%$ & $82.5 \%$ \\
\hline ... Has USA Citizenship & $66.6 \%$ & $65.9 \%$ & $6.5 \%$ & $58.2 \%$ & $75.9 \%$ \\
\hline ... Has Children & $5.1 \%$ & $4.9 \%$ & $3.3 \%$ & $1.3 \%$ & $9.7 \%$ \\
\hline ... Has a Partner & $41.5 \%$ & $42.0 \%$ & $7.7 \%$ & $31.7 \%$ & $50.7 \%$ \\
\hline Share of Section older than 30 & $6.1 \%$ & $5.8 \%$ & $3.8 \%$ & $1.3 \%$ & $10.7 \%$ \\
\hline Average Maximum Risk Score & $38.6 \%$ & $39.0 \%$ & $3.1 \%$ & $34.4 \%$ & $42.2 \%$ \\
\hline Share of Section Having Attended an Ivy League College & $24.2 \%$ & $24.1 \%$ & $5.5 \%$ & $18.1 \%$ & $31.8 \%$ \\
\hline Share of Section Having Attended an Ivy Plus College & $34.4 \%$ & $34.4 \%$ & $6.5 \%$ & $25.3 \%$ & $42.7 \%$ \\
\hline Share of Section with Economics Major at College & $22.6 \%$ & $22.6 \%$ & $5.7 \%$ & $15.9 \%$ & $29.4 \%$ \\
\hline Share of Post-MBA Entrepreneurs & $4.5 \%$ & $4.2 \%$ & $3.5 \%$ & $0.0 \%$ & $7.9 \%$ \\
\hline Share of Successful Post-MBA Entrep & $0.6 \%$ & $0.0 \%$ & $1.0 \%$ & $0.0 \%$ & $1.4 \%$ \\
\hline Share of Post- but Not Pre-MBA Entrepreneurs & $3.7 \%$ & $2.9 \%$ & $3.7 \%$ & $0.0 \%$ & $8.4 \%$ \\
\hline Share of Successful Post-but Not Pre-MBA Entrepreneurs & $0.6 \%$ & $0.0 \%$ & $1.0 \%$ & $0.0 \%$ & $1.5 \%$ \\
\hline Panel B. Sections with at least 70 class cards (60 sections) & Mean & Median & St. Dev. & $\begin{array}{r}\text { 10th } \\
\text { Percentile }\end{array}$ & $\begin{array}{r}90 t h \\
\text { Percentile }\end{array}$ \\
\hline$\overline{\text { Share tl }}$ & 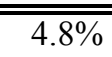 & $4.6 \%$ & $2.9 \%$ & $1.3 \%$ & $8.6 \%$ \\
\hline ... in Consulting & $24.0 \%$ & $23.6 \%$ & $4.1 \%$ & $19.5 \%$ & $28.3 \%$ \\
\hline$\ldots$ in Investment Banking & $18.3 \%$ & $18.4 \%$ & $3.7 \%$ & $13.5 \%$ & $23.0 \%$ \\
\hline$\ldots$ in Private Equity & $5.1 \%$ & $4.3 \%$ & $3.1 \%$ & $1.3 \%$ & $9.4 \%$ \\
\hline Share of Section that is Male & $67.2 \%$ & $67.3 \%$ & $3.1 \%$ & $63.5 \%$ & $71.0 \%$ \\
\hline ... Has USA Citizenship & $64.9 \%$ & $64.7 \%$ & $5.4 \%$ & $58.2 \%$ & $72.6 \%$ \\
\hline ... Has Children & $4.7 \%$ & $4.4 \%$ & $3.0 \%$ & $1.3 \%$ & $9.1 \%$ \\
\hline ... Has a Partner & $42.7 \%$ & $43.3 \%$ & $7.3 \%$ & $33.3 \%$ & $51.3 \%$ \\
\hline Share of Section olde & $5.0 \%$ & $4.9 \%$ & $2.5 \%$ & $1.3 \%$ & $8.2 \%$ \\
\hline Average Maximum & $38.9 \%$ & $39.6 \%$ & $2.7 \%$ & $35.4 \%$ & $42.0 \%$ \\
\hline Share of Section Having Attended a & $24.0 \%$ & $24.1 \%$ & $4.1 \%$ & $19.4 \%$ & $29.1 \%$ \\
\hline Share of Section Having Attended & $34.7 \%$ & $34.3 \%$ & $5.5 \%$ & $27.4 \%$ & $42.2 \%$ \\
\hline Share of Section with Economics Major at College & $22.2 \%$ & $22.3 \%$ & $4.5 \%$ & $16.2 \%$ & $28.2 \%$ \\
\hline Share of Post-MBA Entrepreneurs & $4.8 \%$ & $4.2 \%$ & $3.8 \%$ & $0.0 \%$ & $10.2 \%$ \\
\hline Share of Successful Post-MBA Entrepreneurs & $0.4 \%$ & $0.0 \%$ & $0.7 \%$ & $0.0 \%$ & $1.4 \%$ \\
\hline Share of Post- but Not Pre-MBA Entrepreneurs & $3.9 \%$ & $2.8 \%$ & $4.1 \%$ & $0.0 \%$ & $10.6 \%$ \\
\hline Share of Successful Post-but Not Pre-MBA Entrepreneurs & $0.3 \%$ & $0.0 \%$ & $0.7 \%$ & $0.0 \%$ & $1.4 \%$ \\
\hline
\end{tabular}

Notes. The sample contains the classes of 1997-2004. 
Table III. Predicting the Share of Pre-MBA Entrepreneurs

\begin{tabular}{|c|c|c|}
\hline & Baseline & Alternative \\
\hline Share that worked pre-MBA in consulting & $\begin{array}{l}-0.11 \\
{[0.08]}\end{array}$ & \\
\hline$\ldots$ in investment banking & $\begin{array}{c}0.02 \\
{[0.07]}\end{array}$ & \\
\hline ... in private equity & $\begin{array}{l}-0.17 \\
{[0.14]}\end{array}$ & \\
\hline Share that is male & $\begin{array}{c}0.19 \\
{[0.08]^{* *}}\end{array}$ & \\
\hline ... has US citizenship & $\begin{array}{l}-0.02 \\
{[0.07]}\end{array}$ & \\
\hline ... has children & $\begin{array}{l}-0.11 \\
{[0.12]}\end{array}$ & \\
\hline$\ldots$ has a partner & $\begin{array}{c}0.07 \\
{[0.07]}\end{array}$ & \\
\hline Average maximum risk score & $\begin{array}{c}0.08 \\
{[0.13]}\end{array}$ & \\
\hline Share that attended an Ivy League college & $\begin{array}{c}-0.1 \\
{[0.12]}\end{array}$ & \\
\hline Share that attended an Ivy Plus college & $\begin{array}{l}-0.04 \\
{[0.10]}\end{array}$ & \\
\hline Share with engineering major in college & $\begin{array}{c}-0.18 \\
{[0.07]^{* *}}\end{array}$ & \\
\hline Share that worked in agricultural business & $\begin{array}{c}-0.59 \\
{[0.16]^{* * *}}\end{array}$ & $\begin{array}{c}-0.54 \\
{[0.15]^{* * *}}\end{array}$ \\
\hline Share that worked in health care & $\begin{array}{c}0.39 \\
{[0.13]^{* * *}}\end{array}$ & $\begin{array}{c}0.45 \\
{[0.11]^{* * *}}\end{array}$ \\
\hline Share older than 30 & & $\begin{array}{c}0.25 \\
{[0.09]^{* * *}}\end{array}$ \\
\hline Share that worked as consultant & & $\begin{array}{c}-0.11 \\
{[0.05]^{* *}}\end{array}$ \\
\hline Share that worked in hardware manufacturing & & $\begin{array}{c}0.36 \\
{[0.16]^{* *}}\end{array}$ \\
\hline Year fixed effects & yes & yes \\
\hline Observations & 60 & 60 \\
\hline R-squared & 0.46 & 0.47 \\
\hline F-test (excluding year effects) & $4.10(0.00,13)$ & $11.63(0.00,6)$ \\
\hline
\end{tabular}

Notes. Robust standard errors in brackets. All section-level measures include preMBA entrepreneurs. For the list of additional controls considered, see the text. We report the F-tests for the joint significance of all control variables excluding year effects (F-statistic and, in parentheses, the p-value and the number of constraints). 
Table IV. Correlation Coefficients

\begin{tabular}{|c|c|c|}
\hline & $\begin{array}{c}\text { Share of post-MBA } \\
\text { entrepreneurs }\end{array}$ & $\begin{array}{c}\text { Share of successful } \\
\text { post-MBA } \\
\text { entrepreneurs }\end{array}$ \\
\hline Share of post-MBA entrepreneurs & 1.00 & \\
\hline Share of successful post-MBA entrepreneurs & $\begin{array}{c}0.19 \\
(0.039)\end{array}$ & 1.00 \\
\hline \multicolumn{3}{|l|}{ Share that worked pre-MBA } \\
\hline$\ldots$ as an entrepreneur & $\begin{array}{c}-0.33 \\
(0.000)\end{array}$ & $\begin{array}{c}0.12 \\
(0.199)\end{array}$ \\
\hline$\ldots$ in consulting & $\begin{array}{c}-0.13 \\
(0.156)\end{array}$ & $\begin{array}{c}-0.07 \\
(0.483)\end{array}$ \\
\hline ... investment banking & $\begin{array}{c}-0.13 \\
(0.151)\end{array}$ & $\begin{array}{c}-0.13 \\
(0.174)\end{array}$ \\
\hline ... private equity & $\begin{array}{c}-0.08 \\
(0.405)\end{array}$ & $\begin{array}{c}0.02 \\
(0.810)\end{array}$ \\
\hline Share that is male & $\begin{array}{c}0.33 \\
(0.000)\end{array}$ & $\begin{array}{c}0.05 \\
(0.624)\end{array}$ \\
\hline ... has USA citizenship & $\begin{array}{c}0.24 \\
(0.009)\end{array}$ & $\begin{array}{c}0.00 \\
(0.975)\end{array}$ \\
\hline ... has children & $\begin{array}{c}0.25 \\
(0.007)\end{array}$ & $\begin{array}{c}0.11 \\
(0.243)\end{array}$ \\
\hline ... has a partner & $\begin{array}{c}-0.13 \\
(0.160)\end{array}$ & $\begin{array}{c}0.04 \\
(0.646)\end{array}$ \\
\hline Average maximum risk score & $\begin{array}{c}-0.04 \\
(0.665)\end{array}$ & $\begin{array}{c}0.12 \\
(0.185)\end{array}$ \\
\hline Share that attended an Ivy League college & $\begin{array}{c}-0.04 \\
(0.662)\end{array}$ & $\begin{array}{c}-0.23 \\
(0.012)\end{array}$ \\
\hline Share that attended an Ivy Plus college & $\begin{array}{c}-0.06 \\
(0.494)\end{array}$ & $\begin{array}{c}-0.21 \\
(0.023)\end{array}$ \\
\hline Share of non-entrepreneurs with major in Engineering & $\begin{array}{c}-0.21 \\
(0.021)\end{array}$ & $\begin{array}{c}-0.05 \\
(0.563)\end{array}$ \\
\hline Share of non-entrepreneurs that worked in agricultura & $\begin{array}{c}0.15 \\
(0.103)\end{array}$ & $\begin{array}{c}0.06 \\
(0.498)\end{array}$ \\
\hline Share of non-entrepreneurs that worked in health serv & $\begin{array}{c}0.04 \\
(0.698)\end{array}$ & $\begin{array}{c}-0.06 \\
(0.514)\end{array}$ \\
\hline IPO proceeds in graduation year ( $\$$ trillion) & $\begin{array}{c}0.57 \\
(0.000)\end{array}$ & $\begin{array}{c}0.16 \\
(0.079)\end{array}$ \\
\hline Total venture funding in graduation year ( $\$$ trillion) & $\begin{array}{c}0.70 \\
(0.000) \\
\end{array}$ & $\begin{array}{c}0.22 \\
(0.017) \\
\end{array}$ \\
\hline
\end{tabular}

Notes. The sample includes all 60 sections of the classes of 1997-2004, for which we obtained at least 70 class cards. All section-level measures (except the share that worked pre-MBA as an entrepreneur) do not include pre-MBA entrepreneurs. P-values in parentheses, 
Table V. Determinants of Post-MBA Entrepreneurship

\begin{tabular}{|c|c|c|c|c|c|c|}
\hline \multirow{2}{*}{ Dependent Variable: } & \multicolumn{6}{|c|}{ Share of post-MBA entrepreneurs net of ... } \\
\hline & \multicolumn{3}{|c|}{ identified share of pre-and-post-MBA entrepr. } & \multicolumn{3}{|c|}{ av. estim. share of pre-and-post-MBA entrepr. } \\
\hline \multirow[t]{2}{*}{ Share of section with entrepreneurial background } & -0.46 & -0.35 & -0.34 & -0.55 & -0.44 & -0.44 \\
\hline & {$[0.13]^{* * *}$} & {$[0.11]^{* * *}$} & {$[0.12]^{* * *}$} & {$[0.12]^{* * *}$} & {$[0.11]^{* * *}$} & {$[0.12]^{* * *}$} \\
\hline \multirow[t]{2}{*}{ Share of non-entrepreneurs with consulting background } & -0.11 & -0.06 & -0.04 & -0.03 & -0.07 & -0.05 \\
\hline & {$[0.11]$} & {$[0.09]$} & {$[0.10]$} & {$[0.09]$} & {$[0.07]$} & {$[0.08]$} \\
\hline \multirow[t]{2}{*}{... non-entrepreneurs with inv. banking background } & -0.07 & -0.19 & -0.19 & -0.06 & -0.18 & -0.16 \\
\hline & {$[0.10]$} & {$[0.10]^{*}$} & {$[0.11]^{*}$} & {$[0.09]$} & {$[0.09]^{* *}$} & {$[0.09]^{*}$} \\
\hline \multirow{2}{*}{... non-entrepreneurs with private equity background } & 0.30 & 0.03 & 0.02 & 0.26 & 0.01 & 0.01 \\
\hline & {$[0.14]^{* *}$} & {$[0.16]$} & {$[0.16]$} & {$[0.11]^{* *}$} & {$[0.13]$} & {$[0.13]$} \\
\hline \multirow[t]{2}{*}{... non-entrepreneurs that are male } & 0.54 & 0.84 & 0.90 & 0.49 & 0.79 & 0.85 \\
\hline & {$[0.12]^{* * *}$} & {$[0.21]^{* * *}$} & {$[0.22]^{* * *}$} & {$[0.11]^{* * *}$} & {$[0.17]^{* * *}$} & {$[0.18]^{* * *}$} \\
\hline \multirow[t]{2}{*}{... non-entrepreneurs that are U.S. citizens } & 0.05 & 0.19 & 0.23 & 0.08 & 0.19 & 0.22 \\
\hline & {$[0.07]$} & {$[0.11]^{*}$} & {$[0.12]^{*}$} & {$[0.06]$} & {$[0.08]^{* *}$} & {$[0.09]^{* *}$} \\
\hline \multirow{2}{*}{... non-entrepreneurs with children } & 0.03 & 0.22 & 0.19 & 0.05 & 0.21 & 0.18 \\
\hline & {$[0.16]$} & {$[0.17]$} & {$[0.17]$} & {$[0.14]$} & {$[0.13]$} & {$[0.14]$} \\
\hline \multirow[t]{2}{*}{... non-entrepreneurs with a partner } & -0.11 & -0.19 & -0.19 & -0.17 & -0.22 & -0.23 \\
\hline & {$[0.06]^{*}$} & {$[0.08]^{* *}$} & {$[0.08]^{* *}$} & {$[0.05]^{* * *}$} & {$[0.06]^{* * *}$} & {$[0.07]^{* * *}$} \\
\hline \multirow[t]{2}{*}{... non-entrepreneurs that attended an Ivy League college } & 0.09 & 0.22 & 0.19 & 0.06 & 0.18 & 0.13 \\
\hline & {$[0.14]$} & {$[0.14]$} & {$[0.17]$} & {$[0.12]$} & {$[0.12]$} & {$[0.14]$} \\
\hline \multirow[t]{2}{*}{... non-entrepreneurs that attended an Ivy Plus college } & -0.01 & -0.09 & -0.07 & -0.02 & -0.13 & -0.10 \\
\hline & {$[0.12]$} & {$[0.12]$} & {$[0.14]$} & {$[0.10]$} & {$[0.09]$} & {$[0.11]$} \\
\hline \multirow[t]{2}{*}{... non-entrepreneurs that worked in agricultural business } & -0.46 & -0.64 & -0.43 & -0.45 & -0.63 & -0.54 \\
\hline & {$[0.25]^{*}$} & {$[0.30]^{* *}$} & {$[0.62]$} & {$[0.21]^{* *}$} & {$[0.22]^{* * *}$} & {$[0.44]$} \\
\hline \multirow[t]{2}{*}{... non-entrepreneurs that worked in health care } & 0.53 & 0.58 & 0.62 & 0.51 & 0.56 & 0.60 \\
\hline & {$[0.28]^{*}$} & {$[0.25]^{* *}$} & {$[0.28]^{* *}$} & {$[0.24]^{* *}$} & {$[0.20]^{* * *}$} & {$[0.23]^{* *}$} \\
\hline \multirow[t]{2}{*}{... non-entrepreneurs with major in engineering in college } & 0.08 & -0.03 & -0.02 & 0.10 & 0.00 & 0.00 \\
\hline & {$[0.08]$} & {$[0.10]$} & {$[0.10]$} & {$[0.07]$} & {$[0.08]$} & {$[0.08]$} \\
\hline \multirow[t]{2}{*}{ Mean maximum risk score of section } & -0.22 & -0.28 & -0.25 & -0.17 & -0.22 & -0.20 \\
\hline & {$[0.14]$} & {$[0.15]^{*}$} & {$[0.16]$} & {$[0.12]$} & {$[0.11]^{*}$} & {$[0.12]^{*}$} \\
\hline \multirow[t]{2}{*}{ Total IPO proceeds in graduation year ( $\$$ trillions) } & -1.52 & & & -1.51 & & \\
\hline & {$[0.50]^{* * *}$} & & & {$[0.42]^{* * *}$} & & \\
\hline \multirow[t]{2}{*}{ Total venture financing in graduation year } & 1.35 & & & 1.26 & & \\
\hline & {$[0.27]^{* * *}$} & & & {$[0.22]^{* * *}$} & & \\
\hline Year dummies & & $\mathrm{X}$ & $\mathrm{X}$ & & $\mathrm{X}$ & $\mathrm{X}$ \\
\hline Selected interactions of stratification variables & & & $\mathrm{X}$ & & & $\mathrm{X}$ \\
\hline Regression type & Tobit & OLS & OLS & Tobit & OLS & OLS \\
\hline Observations & 60 & 60 & 60 & 60 & 60 & 60 \\
\hline R-squared & & 0.75 & 0.76 & & 0.83 & 0.83 \\
\hline
\end{tabular}

Notes. All section-level measures (except for pre-MBA entrepreneurs) do not include pre-MBA entrepreneurs. The sample consists of all sections with at least 70 available class cards. The selected set of stratification variables included as interactions contains the share of section that is male, that are U.S. citizens, with a partner, and with investment banking background. Robust standard errors in brackets. * significant at $10 \%$; ** significant at $5 \%$; *** significant at $1 \%$ 
$\underline{\text { Table VI. Determinants of Unsuccessful versus Successful Post-MBA Entrepreneurship }}$

Panel A. Unsuccessful Entrepreneurship

\begin{tabular}{|c|c|c|c|c|c|c|}
\hline \multirow{2}{*}{ Dependent Variable: } & \multicolumn{6}{|c|}{ Share of unsuccessful post-MBA entrepreneurs net of ... } \\
\hline & \multicolumn{3}{|c|}{ identified share of pre-and-post-MBA entrepr. } & \multicolumn{3}{|c|}{ av. est. share of pre-and-post-MBA entrepr. } \\
\hline \multirow[t]{2}{*}{ Share of section with entrepreneurial background } & -0.46 & -0.36 & -0.36 & -0.58 & -0.43 & -0.43 \\
\hline & {$[0.14]^{* * *}$} & {$[0.11]^{* * *}$} & {$[0.11]^{* * *}$} & {$[0.13]^{* * *}$} & {$[0.10]^{* * *}$} & {$[0.11]^{* * *}$} \\
\hline \multirow[t]{2}{*}{ Share of non-entrepreneurs with consulting background } & -0.07 & -0.03 & -0.01 & -0.01 & -0.02 & 0.00 \\
\hline & {$[0.12]$} & {$[0.09]$} & {$[0.10]$} & {$[0.10]$} & {$[0.07]$} & {$[0.08]$} \\
\hline \multirow[t]{2}{*}{... non-entrepreneurs with inv. banking background } & -0.02 & -0.17 & -0.16 & -0.01 & -0.15 & -0.13 \\
\hline & {$[0.10]$} & {$[0.10]$} & {$[0.11]$} & {$[0.09]$} & {$[0.08]^{*}$} & {$[0.09]$} \\
\hline \multirow[t]{2}{*}{... non-entrepreneurs with private equity background } & 0.29 & 0.01 & 0.00 & 0.28 & 0.02 & 0.03 \\
\hline & {$[0.15]^{*}$} & {$[0.17]$} & {$[0.16]$} & {$[0.11]^{* *}$} & {$[0.13]$} & {$[0.12]$} \\
\hline \multirow[t]{2}{*}{... non-entrepreneurs that are male } & 0.63 & 0.81 & 0.85 & 0.50 & 0.75 & 0.79 \\
\hline & {$[0.13]^{* * *}$} & {$[0.20]^{* * *}$} & {$[0.22]^{* * *}$} & {$[0.11]^{* * *}$} & {$[0.15]^{* * *}$} & {$[0.16]^{* * *}$} \\
\hline \multirow[t]{2}{*}{... non-entrepreneurs that are U.S. citizens } & 0.06 & 0.23 & 0.26 & 0.09 & 0.22 & 0.24 \\
\hline & {$[0.07]$} & {$[0.10]^{* *}$} & {$[0.11]^{* *}$} & {$[0.06]^{*}$} & {$[0.07]^{* * *}$} & {$[0.08]^{* * *}$} \\
\hline \multirow{2}{*}{... non-entrepreneurs with children } & 0.09 & 0.23 & 0.20 & 0.09 & 0.23 & 0.21 \\
\hline & {$[0.17]$} & {$[0.16]$} & {$[0.17]$} & {$[0.14]$} & {$[0.12]^{*}$} & {$[0.13]$} \\
\hline \multirow[t]{2}{*}{... non-entrepreneurs with a partner } & -0.11 & -0.20 & -0.20 & -0.18 & -0.23 & -0.23 \\
\hline & {$[0.06]^{*}$} & {$[0.08]^{* *}$} & {$[0.08]^{* *}$} & {$[0.05]^{* * *}$} & {$[0.06]^{* * *}$} & {$[0.06]^{* * *}$} \\
\hline \multirow{2}{*}{... non-entrepreneurs that attended an Ivy League college } & 0.18 & 0.30 & 0.28 & 0.09 & 0.26 & 0.22 \\
\hline & {$[0.15]$} & {$[0.14]^{* *}$} & {$[0.17]$} & {$[0.12]$} & {$[0.10]^{* *}$} & {$[0.13]^{*}$} \\
\hline \multirow[t]{2}{*}{... non-entrepreneurs that attended an Ivy Plus college } & 0.01 & -0.08 & -0.08 & -0.02 & -0.14 & -0.12 \\
\hline & {$[0.11]$} & {$[0.11]$} & {$[0.14]$} & {$[0.09]$} & {$[0.08]^{*}$} & {$[0.10]$} \\
\hline \multirow[t]{2}{*}{... non-entrepreneurs that worked in agricultural business } & -0.53 & -0.71 & -0.67 & -0.47 & -0.69 & -0.75 \\
\hline & {$[0.28]^{*}$} & {$[0.30]^{* *}$} & {$[0.62]$} & {$[0.22]^{* *}$} & {$[0.22]^{* * *}$} & {$[0.42]^{*}$} \\
\hline \multirow{2}{*}{... non-entrepreneurs that worked in health care } & 0.69 & 0.66 & 0.65 & 0.60 & 0.66 & 0.67 \\
\hline & {$[0.27]^{* *}$} & {$[0.23]^{* * *}$} & {$[0.26]^{* *}$} & {$[0.23]^{* *}$} & {$[0.18]^{* * *}$} & {$[0.20]^{* * *}$} \\
\hline \multirow[t]{2}{*}{... non-entrepreneurs with major in engineering in college } & 0.14 & 0.00 & 0.01 & 0.13 & 0.02 & 0.02 \\
\hline & {$[0.09]$} & {$[0.10]$} & {$[0.11]$} & {$[0.07]^{*}$} & {$[0.07]$} & {$[0.07]$} \\
\hline \multirow[t]{2}{*}{ Mean maximum risk score of section } & -0.32 & -0.35 & -0.32 & -0.22 & -0.30 & -0.29 \\
\hline & {$[0.15]^{* *}$} & {$[0.15]^{* *}$} & {$[0.15]^{* *}$} & {$[0.11]^{*}$} & {$[0.10]^{* * *}$} & {$[0.11]^{* * *}$} \\
\hline \multirow[t]{2}{*}{ Total IPO proceeds in graduation year ( $\$$ trillions) } & -1.48 & & & -1.54 & & \\
\hline & {$[0.46]^{* * *}$} & & & {$[0.40]^{* * *}$} & & \\
\hline \multirow[t]{2}{*}{ Total venture financing in graduation year } & 1.27 & & & 1.20 & & \\
\hline & {$[0.25]^{* * *}$} & & & {$[0.21]^{* * *}$} & & \\
\hline Year dummies & & $\mathrm{X}$ & $\mathrm{X}$ & & $\mathrm{X}$ & $\mathrm{X}$ \\
\hline Selected interactions of stratification variables & & & $\mathrm{X}$ & & & $\mathrm{X}$ \\
\hline Regression type & Tobit & OLS & OLS & Tobit & OLS & OLS \\
\hline Observations & 60 & 60 & 60 & 60 & 60 & 60 \\
\hline R-squared & & 0.75 & 0.76 & & 0.84 & 0.85 \\
\hline
\end{tabular}


Table VI (continued)

\section{Panel B. Successful Entrepreneurship}

\begin{tabular}{|c|c|c|c|c|c|c|}
\hline \multirow{2}{*}{ Dependent Variable: } & \multicolumn{6}{|c|}{ Share of successful post-MBA entrepreneurs net of ... } \\
\hline & \multicolumn{3}{|c|}{ identified share of pre-and-post-MBA entrepr. } & \multicolumn{3}{|c|}{ av. est. share of pre-and-post-MBA entrepr. } \\
\hline \multirow[t]{2}{*}{ Share of section with entrepreneurial background } & 0.11 & 0.03 & 0.04 & 0.12 & 0.03 & 0.04 \\
\hline & {$[0.10]$} & {$[0.03]$} & {$[0.04]$} & {$[0.10]$} & {$[0.03]$} & {$[0.03]$} \\
\hline \multirow[t]{2}{*}{ Share of non-entrepreneurs with consulting background } & -0.1 & -0.04 & -0.03 & -0.09 & -0.03 & -0.03 \\
\hline & {$[0.10]$} & {$[0.03]$} & {$[0.03]$} & {$[0.09]$} & {$[0.03]$} & {$[0.03]$} \\
\hline \multirow[t]{2}{*}{... non-entrepreneurs with inv. banking background } & -0.22 & -0.03 & -0.03 & -0.24 & -0.04 & -0.04 \\
\hline & {$[0.10]^{* *}$} & {$[0.03]$} & {$[0.03]$} & {$[0.10]^{* *}$} & {$[0.03]$} & {$[0.03]$} \\
\hline \multirow[t]{2}{*}{... non-entrepreneurs with private equity background } & 0.12 & 0.03 & 0.03 & 0.03 & 0.01 & 0.01 \\
\hline & {$[0.11]$} & {$[0.03]$} & {$[0.03]$} & {$[0.11]$} & {$[0.03]$} & {$[0.03]$} \\
\hline \multirow[t]{2}{*}{... non-entrepreneurs that are male } & -0.15 & 0.02 & 0.05 & -0.12 & 0.05 & 0.07 \\
\hline & {$[0.13]$} & {$[0.07]$} & {$[0.07]$} & {$[0.12]$} & {$[0.06]$} & {$[0.06]$} \\
\hline \multirow{2}{*}{... non-entrepreneurs that are U.S. citizens } & -0.07 & -0.03 & -0.03 & -0.07 & -0.02 & -0.02 \\
\hline & {$[0.07]$} & {$[0.04]$} & {$[0.04]$} & {$[0.07]$} & {$[0.03]$} & {$[0.04]$} \\
\hline \multirow[t]{2}{*}{... non-entrepreneurs with children } & -0.11 & 0 & -0.01 & -0.18 & -0.02 & -0.03 \\
\hline & {$[0.12]$} & {$[0.03]$} & {$[0.04]$} & {$[0.12]$} & {$[0.03]$} & {$[0.03]$} \\
\hline \multirow[t]{2}{*}{... non-entrepreneurs with a partner } & -0.04 & 0 & 0.00 & -0.03 & 0 & 0.00 \\
\hline & {$[0.05]$} & {$[0.02]$} & {$[0.02]$} & {$[0.05]$} & {$[0.01]$} & {$[0.01]$} \\
\hline \multirow[t]{2}{*}{... non-entrepreneurs that attended an Ivy League college } & -0.07 & -0.07 & -0.09 & -0.12 & -0.08 & -0.10 \\
\hline & {$[0.11]$} & {$[0.04]^{*}$} & {$[0.04]^{*}$} & {$[0.10]$} & {$[0.04]^{* *}$} & {$[0.04]^{* *}$} \\
\hline \multirow[t]{2}{*}{... non-entrepreneurs that attended an Ivy Plus college } & -0.06 & -0.01 & 0.01 & -0.01 & 0.01 & 0.03 \\
\hline & {$[0.08]$} & {$[0.03]$} & {$[0.03]$} & {$[0.08]$} & {$[0.02]$} & {$[0.03]$} \\
\hline \multirow[t]{2}{*}{... non-entrepreneurs that worked in agricultural business } & 0.26 & 0.09 & 0.31 & 0.24 & 0.1 & 0.28 \\
\hline & {$[0.26]$} & {$[0.08]$} & {$[0.13]^{* *}$} & {$[0.24]$} & {$[0.07]$} & {$[0.12]^{* *}$} \\
\hline \multirow[t]{2}{*}{... non-entrepreneurs that worked in healthcare } & -0.47 & -0.1 & -0.05 & -0.48 & -0.14 & -0.09 \\
\hline & {$[0.26]^{*}$} & {$[0.07]$} & {$[0.07]$} & {$[0.24]^{*}$} & {$[0.06]^{* *}$} & {$[0.06]$} \\
\hline \multirow[t]{2}{*}{... non-entrepreneurs with major in engineering in college } & -0.12 & -0.02 & -0.01 & -0.09 & -0.01 & -0.01 \\
\hline & {$[0.08]$} & {$[0.02]$} & {$[0.02]$} & {$[0.08]$} & {$[0.02]$} & {$[0.02]$} \\
\hline \multirow[t]{2}{*}{ Mean maximum risk score of section } & 0.19 & 0.08 & 0.09 & 0.21 & 0.09 & 0.10 \\
\hline & {$[0.11]^{*}$} & {$[0.04]^{* *}$} & {$[0.04]^{* *}$} & {$[0.11]^{*}$} & {$[0.03]^{* *}$} & {$[0.03]^{* * *}$} \\
\hline \multirow[t]{2}{*}{ Total IPO proceeds in graduation year ( $\$$ trillions) } & 0.23 & & & 0.06 & & \\
\hline & {$[0.50]$} & & & {$[0.45]$} & & \\
\hline \multirow[t]{2}{*}{ Total venture financing in graduation year } & 0.28 & & & 0.32 & & \\
\hline & {$[0.24]$} & & & {$[0.22]$} & & \\
\hline Year dummies & & $\mathrm{X}$ & $\mathrm{X}$ & & $\mathrm{X}$ & $\mathrm{X}$ \\
\hline Selected interactions of stratification variables & & & $\mathrm{X}$ & & & $\mathrm{X}$ \\
\hline Regression type & Tobit & OLS & OLS & Tobit & OLS & OLS \\
\hline Observations & 60 & 60 & 60 & 60 & 60 & 60 \\
\hline R-squared & & 0.30 & 0.40 & & 0.38 & 0.47 \\
\hline
\end{tabular}


$\underline{\text { Table VI (continued) }}$

Share of post-MBA entrepreneurs net of ...

identified share of pre-and-post-MBA entrepr.

av. estim. share of pre-and-post-MBA entrepr.

p-Value, test of difference in successful and unsuccessful regressions:

Share of section with entrepreneurial background $\quad 0.000$

Joint test of all variables

0.000

0.000

0.000

0.000

0.000

0.000

0.000

0.000

0.000

0.000

0.000

Notes. All section-level measures (except the share with entrepreneurial background) do not include pre-MBA entrepreneurs. The sample consists of all sections with at least 70 class cards. The selected set of stratification variables included as interactions contains the share of section that is male, that are U.S. citizens, with a partner, and with investment banking background. Robust standard errors are in brackets. * significant at $10 \%$; ** significant at $5 \%$; *** significant at $1 \%$. 
Table VII. Alternative Success Measures and Alternative Outcome (Elective Courses)

\begin{tabular}{|c|c|c|c|}
\hline \multirow[t]{2}{*}{ Dependent Variable: } & \multicolumn{2}{|c|}{$\begin{array}{c}\text { Share of post-MBA entrepreneurs (net of } \\
\text { identified pre-and-post-MBA entrepreneurs) } \\
\text { who were ... }\end{array}$} & \multirow{2}{*}{$\begin{array}{l}\text { Enrollment in } \\
\text { entrepreneurship } \\
\text { classes by non-pre- } \\
\text { MBA entrepr. }\end{array}$} \\
\hline & $\frac{\text { not "super"- }}{\text { successful }}$ & "super"-successful & \\
\hline Share of section with entrepreneurial background & $\begin{array}{c}-0.36 \\
{[0.12]^{* * *}}\end{array}$ & $\begin{array}{c}0.03 \\
{[0.02]^{*}}\end{array}$ & $\begin{array}{c}0.02 \\
{[0.08]}\end{array}$ \\
\hline Share of non-entrepreneurs ... & & & \\
\hline ... with consulting background & $\begin{array}{l}-0.06 \\
{[0.11]}\end{array}$ & $\begin{array}{c}0.00 \\
{[0.01]}\end{array}$ & $\begin{array}{c}0.10 \\
{[0.09]}\end{array}$ \\
\hline ... with investment banking background & $\begin{array}{l}-0.20 \\
{[0.13]}\end{array}$ & $\begin{array}{c}0.00 \\
{[0.02]}\end{array}$ & $\begin{array}{l}-0.09 \\
{[0.08]}\end{array}$ \\
\hline ... with private equity background & $\begin{array}{c}0.03 \\
{[0.17]}\end{array}$ & $\begin{array}{c}0.01 \\
{[0.02]}\end{array}$ & $\begin{array}{l}-0.04 \\
{[0.10]}\end{array}$ \\
\hline$\ldots$ that are male & $\begin{array}{c}0.85 \\
{[0.24]^{* * *}}\end{array}$ & $\begin{array}{l}-0.02 \\
{[0.03]}\end{array}$ & $\begin{array}{c}-0.27 \\
{[0.15]^{*}}\end{array}$ \\
\hline ... that are U.S. citizens & $\begin{array}{c}0.22 \\
{[0.13]}\end{array}$ & $\begin{array}{c}-0.03 \\
{[0.02]^{*}}\end{array}$ & $\begin{array}{c}-0.12 \\
{[0.09]}\end{array}$ \\
\hline ... with children & $\begin{array}{c}0.19 \\
{[0.16]}\end{array}$ & $\begin{array}{c}0.03 \\
{[0.02]}\end{array}$ & $\begin{array}{c}0.11 \\
{[0.11]}\end{array}$ \\
\hline ... with a partner & $\begin{array}{c}-0.18 \\
{[0.07]^{* *}}\end{array}$ & $\begin{array}{c}-0.02 \\
{[0.01]^{* *}}\end{array}$ & $\begin{array}{l}-0.06 \\
{[0.05]}\end{array}$ \\
\hline ... that attended an Ivy League college & $\begin{array}{c}0.26 \\
{[0.16]}\end{array}$ & $\begin{array}{c}-0.04 \\
{[0.02]^{*}}\end{array}$ & $\begin{array}{c}0.12 \\
{[0.15]}\end{array}$ \\
\hline$\ldots$ that attended an Ivy Plus college & $\begin{array}{l}-0.11 \\
{[0.12]}\end{array}$ & $\begin{array}{c}0.01 \\
{[0.01]}\end{array}$ & $\begin{array}{l}-0.08 \\
{[0.07]}\end{array}$ \\
\hline ... that worked in agricultural business & $\begin{array}{c}-0.67 \\
{[0.28]^{* *}}\end{array}$ & $\begin{array}{c}0.05 \\
{[0.03]}\end{array}$ & $\begin{array}{l}-0.32 \\
{[0.21]}\end{array}$ \\
\hline ... that worked in health care & $\begin{array}{c}0.61 \\
{[0.28]^{* *}}\end{array}$ & $\begin{array}{l}-0.05 \\
{[0.03]}\end{array}$ & $\begin{array}{l}-0.18 \\
{[0.20]}\end{array}$ \\
\hline ... with major in engineering in college & $\begin{array}{l}-0.03 \\
{[0.10]}\end{array}$ & $\begin{array}{c}0.01 \\
{[0.01]}\end{array}$ & $\begin{array}{c}0.01 \\
{[0.08]}\end{array}$ \\
\hline Mean maximum risk score of section & $\begin{array}{c}-0.29 \\
{[0.16]^{*}}\end{array}$ & $\begin{array}{c}0.02 \\
{[0.02]}\end{array}$ & $\begin{array}{c}0.13 \\
{[0.10]}\end{array}$ \\
\hline Year dummies & $\mathrm{X}$ & $\mathrm{X}$ & $\mathrm{X}$ \\
\hline Regression type & OLS & OLS & OLS \\
\hline $\begin{array}{l}\text { Observations } \\
\text { R-squared }\end{array}$ & $\begin{array}{c}60 \\
0.75 \\
\end{array}$ & $\begin{array}{c}60 \\
0.44 \\
\end{array}$ & $\begin{array}{c}60 \\
0.88 \\
\end{array}$ \\
\hline
\end{tabular}

Notes. OLS regressions on the sample of all sections with at least 70 class cards. All section-level measures (except the share with entrepreneurial background) do not include pre-MBA entrepreneurs. Robust standard errors in brackets. * significant at $10 \% ; * *$ significant at $5 \% ; * * *$ significant at $1 \%$ 


\section{Table VIII. Effects of Successful and Unsuccessful Pre-MBA Entrepreneurship}

Panel A. Effects on Unsuccessful Post-MBA Entrepreneurship

\section{Dependent Variable:}

Share of section with successful entrepreneurial background

Share of section with unsuccessful entrepreneurial background

Full set of control variables

IPO and VC controls

Year dummies

Selected interactions of stratification variables

Regression type

Observations

R-squared
Share of unsuccessful post-MBA entrepreneurs net of ... identified share of pre-and-post-MBA entrepr.

av. est. share of pre-and-post-MBA entrepr.

\begin{tabular}{cccccc}
-0.31 & -0.40 & -0.51 & -0.47 & -0.44 & -0.49 \\
{$[0.29]$} & {$[0.26]$} & {$[0.32]$} & {$[0.22]^{* *}$} & {$[0.18]^{* *}$} & {$[0.22]^{* *}$} \\
-0.59 & -0.31 & -0.22 & -0.66 & -0.42 & -0.37 \\
{$[0.22]^{* * *}$} & {$[0.20]$} & {$[0.27]$} & {$[0.21]^{* * *}$} & {$[0.19]^{* *}$} & {$[0.23]$} \\
$\mathrm{X}$ & $\mathrm{X}$ & $\mathrm{X}$ & $\mathrm{X}$ & $\mathrm{X}$ & $\mathrm{X}$ \\
$\mathrm{X}$ & & $\mathrm{X}$ & & \\
& $\mathrm{X}$ & $\mathrm{X}$ & & $\mathrm{X}$ & $\mathrm{X}$ \\
& & $\mathrm{X}$ & & & $\mathrm{X}$ \\
\hline Tobit & OLS & OLS & Tobit & OLS & OLS \\
60 & 60 & 60 & 60 & 60 & 60 \\
& 0.75 & 0.76 & & 0.84 & 0.85 \\
\hline
\end{tabular}

Panel B. Effects on Successful Post-MBA Entrepreneurship

\begin{tabular}{|c|c|c|c|c|c|c|}
\hline \multirow{3}{*}{$\begin{array}{l}\text { Dependent Variable: } \\
\text { Share of section with successful entrepreneurial background }\end{array}$} & \multicolumn{6}{|c|}{ Share of successful post-MBA entrepreneurs net of ... } \\
\hline & \multicolumn{3}{|c|}{ identified share of pre-and-post-MBA entrepr. } & \multicolumn{3}{|c|}{ av. est. share of pre-and-post-MBA entrepr } \\
\hline & 0.32 & 0.07 & 0.04 & 0.27 & 0.06 & 0.02 \\
\hline & {$[0.20]$} & {$[0.07]$} & {$[0.067]$} & {$[0.18]$} & {$[0.06]$} & {$[0.060]$} \\
\hline \multirow[t]{2}{*}{ Share of section with unsuccessful entrepreneurial background } & -0.05 & -0.01 & 0.05 & 0.00 & 0.01 & 0.06 \\
\hline & {$[0.20]$} & {$[0.06]$} & {$[0.067]$} & {$[0.18]$} & {$[0.06]$} & {$[0.059]$} \\
\hline Full set of control variables & $\mathrm{X}$ & $\mathrm{X}$ & $\mathrm{X}$ & $\mathrm{X}$ & $\mathrm{X}$ & $\mathrm{X}$ \\
\hline IPO and VC controls & $\mathrm{X}$ & & & $\mathrm{X}$ & & \\
\hline Year dummies & & $\mathrm{X}$ & $\mathrm{X}$ & & $\mathrm{X}$ & $\mathrm{X}$ \\
\hline Selected interactions of stratification variables & & & $\mathrm{X}$ & & & $\mathrm{X}$ \\
\hline Regression type & Tobit & OLS & OLS & Tobit & OLS & OLS \\
\hline Observations & 60 & 60 & 60 & 60 & 60 & 60 \\
\hline R-squared & & 0.32 & 0.40 & & 0.38 & 0.47 \\
\hline
\end{tabular}

Notes. All section-level measures (except the share with pre-MBA entrepreneurs) do not include pre-MBA entrepreneurs. The sample consists of all sections with at least 70 class cards. The regressions contain all controls used in Tables V and VII. The selected set of interactions of stratification variables include share of section that is male, are U.S. citizens, with consulting background, with investment banking background, with private equity background, and that attended an Ivy Plus college.

Robust standard errors in brackets. * significant at $10 \%$;* significant at $5 \%$; *** significant at $1 \%$ 
$\underline{\text { Table IX. Variance in Post-MBA Entrepreneurship Rates }}$

\begin{tabular}{lccc}
\hline \hline & $\begin{array}{c}\text { For sections with } \\
\text { below median number } \\
\text { of students with } \\
\text { entrepreneurial } \\
\text { background }\end{array}$ & $\begin{array}{c}\text { For sections with } \\
\text { abedian number } \\
\text { of students with } \\
\text { entrepreneurial } \\
\text { background }\end{array}$ & $\begin{array}{c}\text { p-Value, test } \\
\text { of null } \\
\text { hypothesis } \\
\text { of no } \\
\text { difference }\end{array}$ \\
\hline Standard Deviation of Entrepreneurship Rate & & & \\
Total Post-MBA Entrepreneurship & $4.80 \%$ & $2.90 \%$ & 0.010 \\
Successful Post-MBA Entrepreneurship & $0.63 \%$ & $0.78 \%$ & 0.260 \\
Unsuccessful MBA Entrepreneurship & $4.60 \%$ & $2.80 \%$ & 0.010 \\
\hline \hline
\end{tabular}

Notes. The sample consists of all sections with at least 70 available class cards. 
Appendix Figure 1. Variation in Entrepreneurial Activity

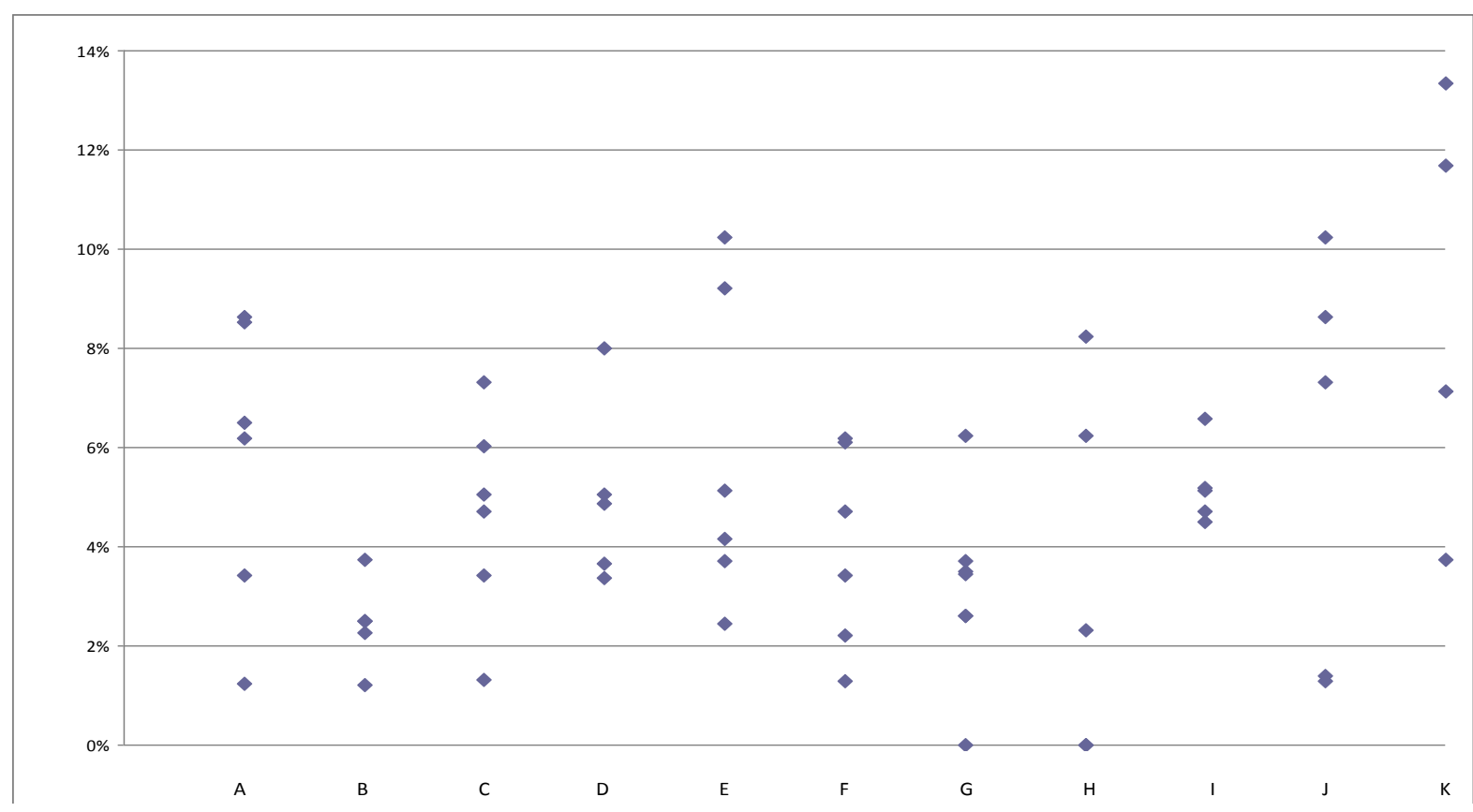

Notes. The graph plots each section-year observation of the rate of pre-MBA entrepreneurs, ordered by section (A to K). The sample contains the 60 sections with 70 or more available class cards. 
Appendix Table A1. Stratification Checks:

Comparing sections with high- and low shares of pre-MBA entrepreneurs

\begin{tabular}{|c|c|c|c|c|}
\hline & \multirow{2}{*}{ Full Sample } & \multicolumn{2}{|c|}{ \# of pre-MBA Entrepreneurs } & \multirow[b]{2}{*}{ p-values } \\
\hline & & below median & above median & \\
\hline Share that ever worked as an entrepreneur & $\begin{array}{c}5.0 \% \\
(3.4 \%)\end{array}$ & $\begin{array}{c}2.4 \% \\
(1.6 \%)\end{array}$ & $\begin{array}{c}7.8 \% \\
(2.6 \%)\end{array}$ & {$[0.000]^{* * *}$} \\
\hline \multicolumn{5}{|l|}{ Share that worked most recently } \\
\hline$\ldots$ in computer hardware & $\begin{array}{c}3.6 \% \\
(2.4 \%)\end{array}$ & $\begin{array}{c}3.3 \% \\
(2.3 \%)\end{array}$ & $\begin{array}{c}3.9 \% \\
(2.6 \%)\end{array}$ & {$[0.252]$} \\
\hline$\ldots$ in computer software & $\begin{array}{c}6.8 \% \\
(3.2 \%)\end{array}$ & $\begin{array}{c}6.5 \% \\
(2.7 \%)\end{array}$ & $\begin{array}{c}7.1 \% \\
(3.7 \%)\end{array}$ & {$[0.334]$} \\
\hline$\ldots$ in computer-related services & $\begin{array}{c}2.6 \% \\
(2.3 \%)\end{array}$ & $\begin{array}{c}2.6 \% \\
(2.3 \%)\end{array}$ & $\begin{array}{c}2.6 \% \\
(2.3 \%)\end{array}$ & {$[0.963]$} \\
\hline$\ldots$ in other high-tech sectors & $\begin{array}{c}1.0 \% \\
(1.4 \%)\end{array}$ & $\begin{array}{c}1.3 \% \\
(1.6 \%)\end{array}$ & $\begin{array}{c}0.7 \% \\
(1.0 \%)\end{array}$ & {$[0.047]^{* *}$} \\
\hline$\ldots$ in telecommunications & $\begin{array}{c}3.2 \% \\
(2.2 \%)\end{array}$ & $\begin{array}{c}3.5 \% \\
(2.1 \%)\end{array}$ & $\begin{array}{c}3.0 \% \\
(2.2 \%)\end{array}$ & {$[0.280]$} \\
\hline$\ldots$ in diversified manufacturing & $\begin{array}{c}1.4 \% \\
(1.3 \%)\end{array}$ & $\begin{array}{c}1.2 \% \\
(1.2 \%)\end{array}$ & $\begin{array}{c}1.5 \% \\
(1.5 \%)\end{array}$ & [0.237] \\
\hline ... in banking & $\begin{array}{l}14.8 \% \\
(5.3 \%)\end{array}$ & $\begin{array}{l}15.1 \% \\
(4.5 \%)\end{array}$ & $\begin{array}{l}14.5 \% \\
(6.1 \%)\end{array}$ & {$[0.635]$} \\
\hline$\ldots$ in financial services & $\begin{array}{c}6.1 \% \\
(2.8 \%)\end{array}$ & $\begin{array}{c}5.5 \% \\
(2.6 \%)\end{array}$ & $\begin{array}{c}6.7 \% \\
(2.9 \%)\end{array}$ & {$[0.062]^{*}$} \\
\hline ... in consulting & $\begin{array}{l}18.3 \% \\
(4.4 \%)\end{array}$ & $\begin{array}{l}18.5 \% \\
(3.8 \%)\end{array}$ & $\begin{array}{l}18.1 \% \\
(5.0 \%)\end{array}$ & {$[0.679]$} \\
\hline ... in technology consulting & $\begin{array}{c}0.4 \% \\
(0.9 \%)\end{array}$ & $\begin{array}{c}0.4 \% \\
(0.8 \%)\end{array}$ & $\begin{array}{c}0.4 \% \\
(1.0 \%)\end{array}$ & {$[0.955]$} \\
\hline ... in venture capital/private equity & $\begin{array}{c}8.0 \% \\
(4.7 \%)\end{array}$ & $\begin{array}{c}8.4 \% \\
(4.3 \%)\end{array}$ & $\begin{array}{c}7.6 \% \\
(5.0 \%)\end{array}$ & {$[0.404]$} \\
\hline$\ldots$ in military & $\begin{array}{c}3.2 \% \\
(2.2 \%)\end{array}$ & $\begin{array}{c}3.3 \% \\
(1.9 \%)\end{array}$ & $\begin{array}{c}3.0 \% \\
(2.5 \%)\end{array}$ & {$[0.515]$} \\
\hline$\ldots$ in non-profit organizations & $\begin{array}{c}4.4 \% \\
(2.5 \%)\end{array}$ & $\begin{array}{c}4.1 \% \\
(2.6 \%)\end{array}$ & $\begin{array}{c}4.7 \% \\
(2.4 \%)\end{array}$ & {$[0.306]$} \\
\hline ... in accounting & $\begin{array}{c}1.1 \% \\
(1.5 \%)\end{array}$ & $\begin{array}{c}0.8 \% \\
(1.4 \%)\end{array}$ & $\begin{array}{c}1.3 \% \\
(1.6 \%)\end{array}$ & [0.114] \\
\hline$\ldots$ in law & $\begin{array}{c}0.9 \% \\
(1.3 \%)\end{array}$ & $\begin{array}{c}0.9 \% \\
(1.2 \%)\end{array}$ & $\begin{array}{c}0.9 \% \\
(1.3 \%)\end{array}$ & {$[0.879]$} \\
\hline$\ldots$ in retail & $\begin{array}{c}4.5 \% \\
(2.7 \%)\end{array}$ & $\begin{array}{c}4.5 \% \\
(2.9 \%)\end{array}$ & $\begin{array}{c}4.4 \% \\
(2.6 \%)\end{array}$ & {$[0.882]$} \\
\hline$\ldots$ in advertising/marketing & $\begin{array}{c}2.2 \% \\
(2.2 \%)\end{array}$ & $\begin{array}{c}2.5 \% \\
(2.3 \%)\end{array}$ & $\begin{array}{c}1.9 \% \\
(2.1 \%)\end{array}$ & {$[0.188]$} \\
\hline$\ldots$ in entertainment & $\begin{array}{c}3.9 \% \\
(2.1 \%)\end{array}$ & $\begin{array}{c}4.3 \% \\
(1.9 \%)\end{array}$ & $\begin{array}{c}3.5 \% \\
(2.2 \%)\end{array}$ & {$[0.070]^{*}$} \\
\hline$\ldots$ in agricultural business & $\begin{array}{c}2.3 \% \\
(1.8 \%)\end{array}$ & $\begin{array}{c}2.6 \% \\
(2.0 \%)\end{array}$ & $\begin{array}{c}2.0 \% \\
(1.5 \%)\end{array}$ & {$[0.095]^{*}$} \\
\hline$\ldots$ in health services & $\begin{array}{c}3.2 \% \\
(2.1 \%)\end{array}$ & $\begin{array}{c}2.9 \% \\
(1.8 \%)\end{array}$ & $\begin{array}{c}3.6 \% \\
(2.4 \%)\end{array}$ & {$[0.156]$} \\
\hline$\ldots$ in other industries & $\begin{array}{c}1.4 \% \\
(1.5 \%)\end{array}$ & $\begin{array}{c}1.5 \% \\
(1.5 \%)\end{array}$ & $\begin{array}{c}1.4 \% \\
(1.5 \%)\end{array}$ & {$[0.768]$} \\
\hline
\end{tabular}




\section{Appendix-Table A1 (continued)}

\begin{tabular}{|c|c|c|c|c|}
\hline & \multirow{2}{*}{ Full Sample } & \multicolumn{2}{|c|}{ \# of pre-MBA Entrepreneurs } & \multirow[b]{2}{*}{ p-values } \\
\hline & & below median & above median & \\
\hline Share that attended an Ivy League college & $\begin{array}{l}24.2 \% \\
(5.4 \%)\end{array}$ & $\begin{array}{l}25.3 \% \\
(5.2 \%)\end{array}$ & $\begin{array}{l}22.9 \% \\
(5.4 \%)\end{array}$ & {$[0.035]^{* *}$} \\
\hline ... an Ivy Plus League college & $\begin{array}{l}34.4 \% \\
(6.4 \%)\end{array}$ & $\begin{array}{l}35.7 \% \\
(5.9 \%)\end{array}$ & $\begin{array}{l}32.9 \% \\
(6.8 \%)\end{array}$ & {$[0.046]^{* *}$} \\
\hline Share that is male & $\begin{array}{l}70.2 \% \\
(7.0 \%)\end{array}$ & $\begin{array}{l}69.9 \% \\
(7.3 \%)\end{array}$ & $\begin{array}{l}70.5 \% \\
(6.7 \%)\end{array}$ & {$[0.716]$} \\
\hline$\ldots$ has a partner & $\begin{array}{l}41.5 \% \\
(7.6 \%)\end{array}$ & $\begin{array}{l}42.0 \% \\
(6.7 \%)\end{array}$ & $\begin{array}{l}40.9 \% \\
(8.6 \%)\end{array}$ & {$[0.525]$} \\
\hline ... has a male partner & $\begin{array}{l}32.2 \% \\
(6.1 \%)\end{array}$ & $\begin{array}{l}33.0 \% \\
(5.1 \%)\end{array}$ & $\begin{array}{l}31.4 \% \\
(7.0 \%)\end{array}$ & {$[0.247]$} \\
\hline$\ldots$ has a female partner & $\begin{array}{c}8.9 \% \\
(4.5 \%)\end{array}$ & $\begin{array}{c}8.6 \% \\
(4.2 \%)\end{array}$ & $\begin{array}{l}9.1 \% \\
(4.7 \%)\end{array}$ & {$[0.642]$} \\
\hline Share with business major at college & $\begin{array}{l}23.5 \% \\
(5.8 \%)\end{array}$ & $\begin{array}{l}23.5 \% \\
(6.0 \%)\end{array}$ & $\begin{array}{l}23.6 \% \\
(5.6 \%)\end{array}$ & {$[0.920]$} \\
\hline$\ldots$ with economics major at college & $\begin{array}{l}22.6 \% \\
(5.7 \%)\end{array}$ & $\begin{array}{l}22.3 \% \\
(6.4 \%)\end{array}$ & $\begin{array}{l}22.9 \% \\
(4.8 \%)\end{array}$ & {$[0.677]$} \\
\hline$\ldots$ with engineering major at college & $\begin{array}{l}16.4 \% \\
(4.7 \%)\end{array}$ & $\begin{array}{l}17.3 \% \\
(4.0 \%)\end{array}$ & $\begin{array}{l}15.5 \% \\
(5.3 \%)\end{array}$ & {$[0.081]^{*}$} \\
\hline ... with computer science major at college & $\begin{array}{c}6.1 \% \\
(3.2 \%)\end{array}$ & $\begin{array}{c}5.8 \% \\
(3.2 \%)\end{array}$ & $\begin{array}{c}6.4 \% \\
(3.2 \%)\end{array}$ & {$[0.393]$} \\
\hline ... with mathematics major at college & $\begin{array}{c}2.3 \% \\
(1.9 \%)\end{array}$ & $\begin{array}{c}2.1 \% \\
(1.9 \%)\end{array}$ & $\begin{array}{c}2.4 \% \\
(1.9 \%)\end{array}$ & {$[0.453]$} \\
\hline ... with natural science major at college & $\begin{array}{l}4.1 \% \\
(2.8 \%)\end{array}$ & $\begin{array}{l}4.2 \% \\
(2.0 \%)\end{array}$ & $\begin{array}{c}4.1 \% \\
(3.4 \%)\end{array}$ & {$[0.935]$} \\
\hline$\ldots$ with law major at college & $\begin{array}{c}0.7 \% \\
(0.9 \%)\end{array}$ & $\begin{array}{c}0.7 \% \\
(0.9 \%)\end{array}$ & $\begin{array}{c}0.7 \% \\
(0.9 \%)\end{array}$ & {$[0.740]$} \\
\hline ... with medical science major at college & $\begin{array}{c}0.3 \% \\
(0.7 \%)\end{array}$ & $\begin{array}{c}0.2 \% \\
(0.6 \%)\end{array}$ & $\begin{array}{c}0.4 \% \\
(0.7 \%)\end{array}$ & [0.191] \\
\hline$\ldots$ with humanity major at college & $\begin{array}{c}4.8 \% \\
(2.8 \%)\end{array}$ & $\begin{array}{c}4.4 \% \\
(2.7 \%)\end{array}$ & $\begin{array}{c}5.1 \% \\
(3.0 \%)\end{array}$ & {$[0.265]$} \\
\hline ... with history major at college & $\begin{array}{l}3.7 \% \\
(2.6 \%)\end{array}$ & $\begin{array}{c}4.3 \% \\
(2.8 \%)\end{array}$ & $\begin{array}{l}3.1 \% \\
(2.1 \%)\end{array}$ & {$[0.019]^{* *}$} \\
\hline ... with journalism major at college & $\begin{array}{c}0.5 \% \\
(0.8 \%)\end{array}$ & $\begin{array}{c}0.4 \% \\
(0.7 \%)\end{array}$ & $\begin{array}{c}0.5 \% \\
(0.8 \%)\end{array}$ & {$[0.596]$} \\
\hline$\ldots$ with architecture major at college & $\begin{array}{c}0.3 \% \\
(0.9 \%)\end{array}$ & $\begin{array}{c}0.1 \% \\
(0.4 \%)\end{array}$ & $\begin{array}{c}0.5 \% \\
(1.2 \%)\end{array}$ & {$[0.075]^{*}$} \\
\hline$\ldots$ with political science major at college & $\begin{array}{l}7.9 \% \\
(3.6 \%)\end{array}$ & $\begin{array}{l}7.5 \% \\
(3.9 \%)\end{array}$ & $\begin{array}{c}8.4 \% \\
(3.1 \%)\end{array}$ & {$[0.213]$} \\
\hline$\ldots$ with anthropology major at college & $\begin{array}{c}5.1 \% \\
(3.0 \%)\end{array}$ & $\begin{array}{c}5.5 \% \\
(2.9 \%)\end{array}$ & $\begin{array}{l}4.6 \% \\
(3.0 \%)\end{array}$ & {$[0.158]$} \\
\hline Share that has US citizenship & $\begin{array}{l}66.6 \% \\
(6.5 \%)\end{array}$ & $\begin{array}{l}67.5 \% \\
(6.6 \%)\end{array}$ & $\begin{array}{l}65.6 \% \\
(6.1 \%)\end{array}$ & [0.179] \\
\hline Share of Caucasians & $\begin{array}{c}43.0 \% \\
(11.9 \%)\end{array}$ & $\begin{array}{c}43.7 \% \\
(12.6 \%)\end{array}$ & $\begin{array}{c}42.2 \% \\
(11.1 \%)\end{array}$ & {$[0.573]$} \\
\hline$\ldots$ of Asians & $\begin{array}{c}5.8 \% \\
(2.9 \%)\end{array}$ & $\begin{array}{c}5.7 \% \\
(2.8 \%)\end{array}$ & $\begin{array}{c}6.0 \% \\
(3.0 \%)\end{array}$ & {$[0.651]$} \\
\hline ... of Hispanics & $\begin{array}{l}1.7 \% \\
(1.6 \%)\end{array}$ & $\begin{array}{l}1.9 \% \\
(1.6 \%)\end{array}$ & $\begin{array}{l}1.6 \% \\
(1.5 \%)\end{array}$ & {$[0.322]$} \\
\hline ... of other races & $\begin{array}{c}4.0 \% \\
(2.7 \%)\end{array}$ & $\begin{array}{c}3.9 \% \\
(2.5 \%)\end{array}$ & $\begin{array}{l}4.1 \% \\
(2.8 \%)\end{array}$ & [0.767] \\
\hline
\end{tabular}




\section{Appendix-Table A1 (continued)}

\begin{tabular}{|c|c|c|c|c|}
\hline & \multirow{2}{*}{ Full Sample } & \multicolumn{2}{|c|}{ \# of pre-MBA Entrepreneurs } & \multirow[b]{2}{*}{ p-values } \\
\hline & & below median & above median & \\
\hline \multirow[t]{2}{*}{ Share with age less than 22} & $0.8 \%$ & $0.8 \%$ & $0.9 \%$ & {$[0.807]$} \\
\hline & $(1.1 \%)$ & $(1.1 \%)$ & $(1.2 \%)$ & \\
\hline \multirow[t]{2}{*}{$\ldots$ with age $23-25$} & $55.7 \%$ & $57.1 \%$ & $54.3 \%$ & {$[0.143]$} \\
\hline & $(8.6 \%)$ & $(7.8 \%)$ & $(9.3 \%)$ & \\
\hline \multirow[t]{2}{*}{$\ldots$ with age $26-29$} & $37.1 \%$ & $36.6 \%$ & $37.8 \%$ & {$[0.474]$} \\
\hline & $(7.8 \%)$ & $(7.8 \%)$ & $(7.7 \%)$ & \\
\hline \multirow[t]{2}{*}{$\ldots$ with age 30 and higher } & $6.1 \%$ & $5.3 \%$ & $6.9 \%$ & {$[0.051]^{*}$} \\
\hline & $(3.7 \%)$ & $(3.0 \%)$ & $(4.3 \%)$ & \\
\hline \multirow[t]{2}{*}{ Share who have ever had a function in general mgmt } & $17.4 \%$ & $16.8 \%$ & $18.2 \%$ & {$[0.170]$} \\
\hline & $(4.9 \%)$ & $(4.9 \%)$ & $(4.8 \%)$ & \\
\hline \multirow[t]{2}{*}{$\ldots$ in business consulting } & $18.3 \%$ & $18.8 \%$ & $17.7 \%$ & {$[0.278]$} \\
\hline & $(4.8 \%)$ & $(4.0 \%)$ & $(5.5 \%)$ & \\
\hline \multirow[t]{2}{*}{$\ldots$ in strategic planning } & $4.3 \%$ & $4.8 \%$ & $3.7 \%$ & {$[0.047]^{* *}$} \\
\hline & $(2.7 \%)$ & $(2.6 \%)$ & $(2.7 \%)$ & \\
\hline \multirow[t]{2}{*}{$\ldots$ in corporate finance } & $27.5 \%$ & $28.2 \%$ & $26.7 \%$ & {$[0.306]$} \\
\hline & $(6.3 \%)$ & $(5.9 \%)$ & $(6.8 \%)$ & \\
\hline \multirow[t]{2}{*}{$\ldots$ in marketing } & $9.1 \%$ & $9.1 \%$ & $9.1 \%$ & {$[0.936]$} \\
\hline & $(3.8 \%)$ & $(3.9 \%)$ & $(3.8 \%)$ & \\
\hline \multirow[t]{2}{*}{$\ldots$ in logistics } & $8.2 \%$ & $8.3 \%$ & $8.2 \%$ & {$[0.932]$} \\
\hline & $(3.4 \%)$ & $(3.0 \%)$ & $(3.9 \%)$ & \\
\hline \multirow[t]{2}{*}{$\ldots$ in accounting } & $1.3 \%$ & $1.1 \%$ & $1.7 \%$ & [0.101] \\
\hline & $(1.6 \%)$ & $(1.3 \%)$ & $(1.9 \%)$ & \\
\hline \multirow[t]{2}{*}{$\ldots$ in assorted other areas } & $0.5 \%$ & $0.4 \%$ & $0.5 \%$ & {$[0.541]$} \\
\hline & $(0.8 \%)$ & $(0.8 \%)$ & $(0.9 \%)$ & \\
\hline \multirow[t]{2}{*}{$\ldots$ in engineering } & $3.1 \%$ & $3.1 \%$ & $3.0 \%$ & {$[0.822]$} \\
\hline & $(2.2 \%)$ & $(2.3 \%)$ & $(2.1 \%)$ & \\
\hline \multirow[t]{2}{*}{$\ldots$ in fund-raising } & $0.2 \%$ & $0.1 \%$ & $0.2 \%$ & {$[0.356]$} \\
\hline & $(0.5 \%)$ & $(0.4 \%)$ & $(0.6 \%)$ & \\
\hline \multirow[t]{2}{*}{... in human resources } & $0.3 \%$ & $0.4 \%$ & $0.1 \%$ & {$[0.043]^{* *}$} \\
\hline & $(0.6 \%)$ & $(0.8 \%)$ & $(0.4 \%)$ & \\
\hline \multirow[t]{2}{*}{$\ldots$ in legal services } & $0.9 \%$ & $0.8 \%$ & $0.9 \%$ & {$[0.781]$} \\
\hline & $(1.4 \%)$ & $(1.2 \%)$ & $(1.6 \%)$ & \\
\hline \multirow{2}{*}{... in medical services } & $0.5 \%$ & $0.3 \%$ & $0.7 \%$ & {$[0.033]^{* *}$} \\
\hline & $(0.8 \%)$ & $(0.6 \%)$ & $(0.9 \%)$ & \\
\hline \multirow{2}{*}{$\ldots$ in consulting } & $22.5 \%$ & $22.4 \%$ & $22.6 \%$ & {$[0.869]$} \\
\hline & $(5.4 \%)$ & $(5.3 \%)$ & $(5.4 \%)$ & \\
\hline \multirow[t]{2}{*}{... in investment banking } & $18.7 \%$ & $18.8 \%$ & $18.6 \%$ & [0.849] \\
\hline & $(5.5 \%)$ & $(4.9 \%)$ & $(6.1 \%)$ & \\
\hline \multirow[t]{2}{*}{$\ldots$ in private equity } & $4.6 \%$ & $5.1 \%$ & $4.0 \%$ & {$[0.098]^{*}$} \\
\hline & $(2.9 \%)$ & $(3.0 \%)$ & $(2.8 \%)$ & \\
\hline$\ldots$ in other sectors & $5.7 \%$ & $5.4 \%$ & $6.0 \%$ & {$[0.383]$} \\
\hline & $(2.9 \%)$ & $(2.8 \%)$ & $(3.1 \%)$ & \\
\hline Average maximum risk score & $38.6 \%$ & $38.7 \%$ & $38.6 \%$ & {$[0.874]$} \\
\hline & $(3.1 \%)$ & $(2.6 \%)$ & $(3.5 \%)$ & \\
\hline
\end{tabular}

Notes. The tables shows mean percentages (and standard deviations in parentheses). The sample consists of the 60 sections with at least 70 class cards. The last column shows heteroskedasticity-robust p-values for the test of no difference in means between the subsamples with a below-median and an above-median number of entrepreneurs. All section-level measures include pre-MBA entrepreneurs. 